\title{
Hydrogels based on copolymers of 2- hydroxyethylmethacrylate and 2- hydroxyethylacrylate as a delivery system for proteins: Interactions with lysozyme
}

Article

Accepted Version

Hackl, E. V., Khutoryanskiy, V. and Ermolina, I. (2017) Hydrogels based on copolymers of 2-hydroxyethylmethacrylate and 2-hydroxyethylacrylate as a delivery system for proteins: Interactions with lysozyme. Journal of Applied Polymer Science, 134 (18). 44768. ISSN 0021-8995 doi: https://doi.org/10.1002/app.44768 Available at https://centaur.reading.ac.uk/69513/

It is advisable to refer to the publisher's version if you intend to cite from the work. See Guidance on citing.

Published version at: http://onlinelibrary.wiley.com/doi/10.1002/app.44768/epdf

To link to this article DOI: http://dx.doi.org/10.1002/app.44768

Publisher: Wiley

All outputs in CentAUR are protected by Intellectual Property Rights law, including copyright law. Copyright and IPR is retained by the creators or other copyright holders. Terms and conditions for use of this material are defined in the End User Agreement. 


\section{www.reading.ac.uk/centaur}

\section{CentAUR}

Central Archive at the University of Reading

Reading's research outputs online 


\title{
Hydrogels based on copolymers of 2-hydroxyethylmethacrylate and 2-hydroxyethylacrylate as a delivery system for proteins: interactions with lysozyme
}

Ellen V. Hackla, \#, Vitaliy V. Khutoryanskiy ${ }^{\mathrm{b}}$, Irina Ermolina ${ }^{\mathrm{a}, *}$

${ }^{a}$ Leicester School of Pharmacy, De Montfort University, Leicester, UK

${ }^{\mathrm{b}}$ Reading School of Pharmacy, University of Reading, Reading, UK

* corresponding author; e-mail: iermolina@dmu.ac.uk; School of Pharmacy, Health and Life Science Faculty, Montfort University, The Gateway, Leicester, LE1 9BH, UK

\# present address: Reading School of Pharmacy, University of Reading, Reading, UK

\begin{abstract}
Hydrogels have attracted considerable attention due to numerous applications, in particular as contact lenses and carriers for sustained drug delivery. The aim of the present work is to characterize the interactions of copolymer hydrogels consisted of 2-hydroxyethylmethacrylate (HEMA) and 2hydroxyethylacrylate (HEA) with a small protein (lysozyme) and to assess the potential applications of these hydrogels as a drug delivery system for sustained release of protein-based therapeutics. Physicochemical properties of protein-loaded hydrogels, as well as lysozyme in vitro loading and release and the conformation of the protein released from hydrogels were studied. The effect of copolymer composition on the protein deposition on hydrogels and protein aggregation in the presence of hydrogels was also assessed. The results show that introduction of HEA into the copolymeric hydrogels enhances their suitability as a delivery system for proteins. Copolymerisation of HEMA and HEA allows controlling the physicochemical properties of hydrogels and the protein release rate.
\end{abstract}

Abbreviations: HEA - 2-hydroxyethylacrylate; HEMA - 2-hydroxyethylmethacrylate; DSC Differential Scanning Calorimetry; TGA - Thermogravimetric Analysis; TA - Texture Analysis; FTIR - Fourier-transform infrared spectroscopy; SEM - Scanning Electron Microscopy; OD optical density; ThT - Thioflavin T 


\section{INTRODUCTION}

Hydrogels are three-dimensional polymeric hydrophilic networks, capable of imbibing large amount of water [1]. Due to their biocompatibility and resemblance to natural living tissue, hydrogels have found numerous applications in medicine and pharmaceutical science, including soft contact lenses, carriers for controlled drug release, tissue engineering scaffolds, and matrices for enzyme immobilisation $[1,2,3]$.

Proteins are widely used as therapeutic agents (recombinant proteins with enzymatic or regulatory activity, monoclonal antibodies, bacterial protein antibiotics, vaccines $[4,5]$ and there is great potential for further development of new protein-based pharmaceuticals $[6,7,8]$. Proteins can also be employed as drug delivery agents in protein-based nanoparticles. Unlike synthetic polymers, natural biomolecules present a number of advantages including safety, biocompatibility and biodegradability [9]. Low molecular weight proteins such as lysozyme have also been shown as suitable carriers to target drugs to the kidney [10 and references therein]. For clinical applications the most commonly used small proteins are growth factors and cytokines (wound healing) [11] and transcription factors (regulatory proteins in gene expression) [12].

One of the main problems, which protein pharmaceutics face, is that the serum half-life of recombinant proteins is sometimes insufficiently short as they can be rapidly cleared thus requiring frequent administration. Administering drugs locally rather than systemically using sustained release can be a way to extend their serum half-life and to decrease drug toxicity. Hydrogels potentially can be used as carriers for protein pharmaceutics for topical applications (for example, for a topical antibacterial treatment for a localized infection) and also for oral delivery $[13,14,15]$.

Recently we described the hydrogels prepared by free-radical three-dimensional copolymerisation of 2-hydroxyethylmethacrylate (HEMA) and 2-hydroxyethylacrylate (HEA) [16,17]. We have demonstrated that introduction of hydrophilic HEA significantly changes the morphology and the physicochemical properties of the HEA-HEMA hydrogels. In order to evaluate the HEA-HEMA hydrogels as potential drug delivery systems for sustained release of large biopharmaceuticals, the interaction of hydrogel networks with a model protein (lysozyme) needs to be investigated since the addition of drug molecules (especially large macromolecules like proteins) can adversely affect the physicochemical properties of the hydrogels. 
At the same time, in the "hydrogel - protein" system, a hydrogel, in its turn, can have an impact on the protein behaviour when incubating in a protein solution during loading. In many biomedical applications (contact lenses, blood-contacting implants, drug delivery devices, and artificial organs), hydrogels can be in a prolonged contact with proteins. This contact can be either planned if hydrogels are used as drug delivery systems loaded with biopharmaceutical proteins (therapeutic agents) or unwanted but unavoidable (contact with body liquids, i.e. tears or blood, enriched with proteins). In the latter case proteins can be considered as a contamination. When exposed to a solid surface, protein molecules have a tendency to rearrange their 3D structure and adsorb on the surface in order to lower the Gibbs energy [18]. A protein layer begins to form immediately after hydrogel exposure to a protein solution [19]. This problem is especially important for contact lenses - a protein film formation on the lens surface due to the protein deposition leads to lens spoilage [20, 21, 22]. The latter may cause allergic and inflammatory responses in lens wearers. Lysozyme is the most abundant protein in human tears (about 30\% of the tears total protein content) followed by lactoferrin and tear albumin [23]. It was found that lysozyme is the most prevailing protein in the protein films on the lens surface due to its low molecular weight and positive charge at physiological $\mathrm{pH}[21,24,25,26]$. At the same time a protein contact with the hydrogel surface can also result in partial rearrangements of the protein's native 3D structure and protein destabilisation / unfolding. In its turn, protein unfolding facilitates protein aggregation [27]. Thus, a contact with hydrogel surface can potentially lead to the protein destabilization and aggregation.

In the present work we studied HEA-HEMA hydrogels interactions with a protein, which can be considered from two different points of view: (1) the protein as a drug, which could be delivered using these hydrogels; and (2) the protein in the body liquids (tears or blood) that could interact with the hydrogels. To combine these two aspects, lysozyme has been chosen as a model protein as it is a relatively small biopolymer, which is present in the human body fluids, especially it is abundant in the tear fluid. Moreover, lysozyme is also known as a protein able to form a protein film on different types of contact lens and, therefore, can serve as a good model to study the effect of HEA-HEMA hydrogel composition on protein deposition. In the first part of the study the impact of protein (lysozyme) on different physicochemical and pharmaceutical properties of HEA-HEMA hydrogels was studied and compared with the protein-free hydrogels. Physicochemical (swelling, morphology, the total water content, free/bound water distribution and water retention) and mechanical properties 
of hydrogels loaded with lysozyme were examined using SEM, FTIR, TGA, DSC, gravimetry and texture analysis. Lysozyme in vitro loading/release and the conformation of the protein released from HEA-HEMA hydrogels with different HEA content were analysed using UV-Vis, FTIR, and Thioflavin $\mathrm{T}$ assay. In the second part of the study in order to develop materials with the minimised adverse effects resulting from protein interaction with hydrogels, the effect of hydrogels on the protein was assessed. Specifically, in this part of work we investigated two possible aspects related to the hydrogel effect on proteins: protein deposition onto HEA-HEMA hydrogels; and protein aggregation in the presence of HEA-HEMA hydrogels.

\section{EXPERIMENTAL}

\subsection{Materials}

The 2-hydroxyethylacrylate-co-2-hydroxyethylmethacrylate (HEA-HEMA) hydrogels with different HEA-to-HEMA ratios (HEA content varied from 0 to $100 \mathrm{~mol} \%$ ) were synthesized by threedimensional free-radical copolymerisation of HEA and HEMA, purified and freeze-dried as described previously [16]. Hereinafter the hydrogels are labelled according to the HEA mol \% content in the monomer feed mixture.

10X PBS buffer (pH 7.4) was obtained from Gibco® (UK). Lysozyme from chicken egg white and Thioflavin T were obtained from Sigma-Aldrich (UK). Unless otherwise specified, all materials and reagents used were of analytical grade and were used without further purification.

Freeze-dried HEA-HEMA hydrogel samples were immersed in an excessive volume of the liquid media (150 mM PBS buffer or freshly prepared lysozyme solution in $150 \mathrm{mM}$ PBS) and allowed to fully swell during 10-14 days until the mass of hydrogel became constant over time. Samples were kept at $4{ }^{\circ} \mathrm{C}$ all the time to prevent protein denaturation. The sterile water has been used to prepare the protein solutions and the absence of protein denaturation or aggregation over 14 days of incubation at $4{ }^{\circ} \mathrm{C}$ was confirmed spectrophotometrically. 


\subsection{Methods}

\subsubsection{Swelling of HEA-HEMA hydrogels}

The swelling measurements of the HEA-HEMA hydrogels with different HEA content in $150 \mathrm{mM}$ PBS buffer ( $\mathrm{pH} 7.4)$ containing lysozyme $(10 \mathrm{mg} / \mathrm{mL})$ were performed by conventional gravimetric analysis. In a typical experiment a pre-weighed piece of freeze-dried hydrogel $(30 \pm 10 \mathrm{mg}) \mathrm{was}$ immersed into a swelling medium at $4{ }^{\circ} \mathrm{C}$ and allowed to swell. At regular time intervals swollen hydrogels were quickly took out from the swelling medium (excess water was removed by blotting a sample against plastic weighing boat), weighed and placed in the same medium. The procedure was continued until the equilibrium has been achieved (i.e. until the weight of hydrogel was found to remain constant). Between measurements the samples were kept at constant temperature $\left(4{ }^{\circ} \mathrm{C}\right)$. The swelling degree (SD\%) was calculated as follows:

$$
S D \%=\frac{W_{s}-W_{d}}{W_{d}} \cdot 100 \%
$$

where $W_{s}$ is the weight of a swollen hydrogel; $W_{d}$ is the weight of a dry hydrogel.

\subsubsection{Thermogravimetric analysis (TGA)}

The dynamic weight loss by the fully swollen hydrogels samples and the total amount of water in the samples were measured using the Perkin Elmer Pyris 1 Thermogravimetric Analyzer (USA). All tests were conducted in a $\mathrm{N}_{2}$ gas purge $(20 \mathrm{~mL} / \mathrm{min})$. In a temperature scan experiment a hydrogel sample (25-30 mg) in a sealed and perforated (non-hermetic) aluminium pan was exposed to heat at a rate of $5{ }^{\circ} \mathrm{C} / \mathrm{min}$ in the $25-250^{\circ} \mathrm{C}$ temperature range. Onset and end set temperatures of water evaporation were calculated using Pyris software.

In a separate type of experiments ("loss-on-drying" experiments [17]), the rate of water evaporation from a hydrogel sample at physiological temperature was measured by incubating the fully swollen hydrogel sample (about 25-30 mg) in an open aluminium pan at $37{ }^{\circ} \mathrm{C}$ during $120 \mathrm{~min}$ and measuring weight loss over time. After $2 \mathrm{~h}$ isothermal incubation, the sample was heated from $37^{\circ} \mathrm{C}$ to $250{ }^{\circ} \mathrm{C}$ at $5{ }^{\circ} \mathrm{C} / \mathrm{min}$. Water evaporated during incubation at $37{ }^{\circ} \mathrm{C}$ and the total amount of water in hydrogel samples were calculated. 


\subsubsection{Differential scanning calorimetry (DSC)}

The thermal properties of the hydrogels were examined using the Perkin-Elmer Jade DSC (USA). A fully-swollen hydrogel sample (about $11 \pm 2 \mathrm{mg}$ ) was placed in an aluminium pan and the pan was hermetically sealed. An empty pan was used as a reference. The samples were cooled from 30 to $40{ }^{\circ} \mathrm{C}$ at $2{ }^{\circ} \mathrm{C} / \mathrm{min}$ and held for 3 minutes before returning back to $30^{\circ} \mathrm{C}$ at the same rate. Nitrogen was used as a purge gas at $20 \mathrm{~mL} / \mathrm{min}$. The calorimeter was calibrated using indium standard. The melting/crystallisation temperatures and enthalpy of melting/crystallisation for water in hydrogels were calculated using Pyris software.

\subsubsection{Fourier-transform infrared spectroscopy (ATR-FTIR)}

To assess the secondary structure of lysozyme released from hydrogels, the Attenuated Total Reflectance FTIR spectroscopy was used. IR spectra were recorded over the wavelength range $4000-500 \mathrm{~cm}^{-1}$, with a resolution of $2 \mathrm{~cm}^{-1}$ and 70 scans accumulation, using an FTIR Platinum-ATR spectrometer (Bruker Tensor OPUS 27 FT-IR'). The spectra were corrected for the baseline. To prepare lysozyme samples for FTIR, hydrogels with different HEA content loaded with lysozyme were placed in $1 \mathrm{~mL}$ of distilled water and kept 1-2 days at $4{ }^{\circ} \mathrm{C}$. Then lysozyme concentration in solution was measured and solutions containing lysozyme released from the hydrogels were freezedried. Freshly prepared lysozyme aqueous solution of the same concentration was also freeze-dried using the same cycle and taken as a control. After lyophilisation samples were stored at $4{ }^{\circ} \mathrm{C}$ in dry atmosphere no longer than 48 hours prior to the measurements.

\subsubsection{UV-Vis absorption spectroscopy}

$\mathrm{UV}-\mathrm{Vis}$ absorption spectra or single wavelength absorbance of lysozyme in $150 \mathrm{mM}$ PBS buffer were recorded using a Thermo-Scientific UV-Vis Evolution 60S spectrophotometer in 1-cm pathlength quartz cuvettes, at room temperature $\left(22^{\circ} \mathrm{C}\right)$. The absorption spectrum of the solvent (PBS buffer) was subtracted from the solution absorption spectrum. Protein concentration was calculated from the absorbance of the lysozyme solution at $280 \mathrm{~nm}$ using a percent solution extinction coefficient of $26.4 \mathrm{E} 1 \%$. 


\subsubsection{In vitro protein loading and release assays}

In a typical protein loading experiment, a pre-swollen hydrogel sample (20-50 mg) was weighed and immersed into an excessive volume of the lysozyme solution (in $150 \mathrm{mM}$ PBS buffer, $\mathrm{pH} 7.4$ ) at given temperature $\left(4^{\circ} \mathrm{C}\right.$ or $\left.22^{\circ} \mathrm{C}\right)$. After a fixed time interval the hydrogel sample was very briefly $(<1 \mathrm{sec})$ rinsed in PBS buffer to remove the excessive protein solution from the hydrogel surface, transferred into a fresh aliquot of PBS buffer $(2 \mathrm{~mL})$ and kept at $4{ }^{\circ} \mathrm{C}$. After $24-48$ hours the concentration of protein released was measured spectrophotometrically at $280 \mathrm{~nm}$.

Release studies of the lysozyme have been carried out in vitro by placing a fully swollen and lysozyme-loaded hydrogel sample (about $20 \pm 1.5 \mathrm{mg}$ ) in a fixed volume $(2 \mathrm{~mL})$ of the release medium (150 mM PBS buffer) at room or low $\left(4{ }^{\circ} \mathrm{C}\right)$ temperature. Before placing in the release medium the hydrogel sample was very quickly $(<1 \mathrm{sec})$ pre-washed in small volume $(<100 \mu \mathrm{L})$ of release medium to remove surface water containing extra proteins. The amount of protein released was measured spectrophotometrically at $280 \mathrm{~nm}$ at regular time intervals. The liquid volume was kept constant during the measurement.

\subsubsection{Protein aggregation}

To induce protein aggregation, lysozyme solutions were pre-incubated at room temperature $\left(22{ }^{\circ} \mathrm{C}\right)$ or at $45{ }^{\circ} \mathrm{C}$ for $2-5$ days. Turbidimetry assay at $360 \mathrm{~nm}$ was used to assess the formation of protein aggregates. The presence of aggregates was also confirmed using light microscopy.

\subsubsection{Fluorescence spectroscopy}

ThT assay was used to assess the presence of protein aggregates in solutions. In a typical experiment $20 \mu \mathrm{L}$ of $1 \mathrm{mM}$ Thioflavin $\mathrm{T}$ (ThT) was added to $2 \mathrm{~mL}$ solutions of lysozyme in PBS buffer immediately prior to the measurements. The ThT fluorescence emission spectra were recorded using a LS55 spectrofluorometer (Perkin-Elmer, UK). The temperature inside the 1-cm quartz cuvette was maintained at $24.5^{\circ} \mathrm{C}$ by a thermostated cell holder.

ThT emission spectra were recorded in $0.5 \mathrm{~nm}$ increments by exciting the sample at $445 \mathrm{~nm}$ and collecting the emission between 455 and $650 \mathrm{~nm}$; the excitation and emission slit widths were set at 2.5 and $5 \mathrm{~nm}$, respectively. Final ThT concentration was $10 \mu \mathrm{M}$, and for lysozyme $-10 \mathrm{mg} / \mathrm{mL}$. 


\subsubsection{Texture Analysis}

Mechanical properties of fully swollen (in either $150 \mathrm{mM}$ PBS buffer alone or buffered $2 \mathrm{mg} / \mathrm{mL}$ lysozyme solution) HEA-HEMA hydrogels were studied using Texture Analyser (Stable Micro System TA-XT.plus) in compression mode. A stainless steel cylindrical P/2 probe with a diameter of $2 \mathrm{~mm}$ was pressed into a hydrogel sample and compression force change with distance/time was monitored. The probe pre-test speed of $1 \mathrm{~mm} / \mathrm{s}$, test speed of $0.5 \mathrm{~mm} / \mathrm{s}$ and trigger force of $0.2 \mathrm{~g}$ were used and the distance target mode with a distance of $1.5 \mathrm{~mm}$ was set up during all experiments. The value of stress (the force per unit area) was calculated from the maximum force value:

$$
\text { Stress }=\frac{\text { Force }(\mathrm{g})}{\text { Area }\left(\mathrm{mm}^{2}\right)}
$$

Each hydrogel sample was measured at room temperature 5-7 times and the average value of stress was taken. After penetrating hydrogel sample, the probe was held for $20 \mathrm{sec}$ before releasing the pressure ("on hold" stage) and the force relaxation was calculated as ratio between the forces before and after "on hold" stage.

\subsubsection{Scanning Electron Microscopy (SEM)}

The surface morphology of HEA-HEMA hydrogels swollen in PBS buffer in the presence of lysozyme was examined using Carl Zeiss EVO HD15 Scanning Electron Microscope (UK) with the Peltier Coolstage MK3 (DEBEN UK Ltd) at various magnifications (up to 10K). The temperature and pressure inside the sample chamber were $-21^{\circ} \mathrm{C}$ at $10-15 \mathrm{~Pa}$, respectively. A gel sample was mounted on pre-chilled 12.5 SEM pin metal stub and quickly frozen before images were collected.

To examine the protein deposition, the hydrogels samples were stored for 1.5 months at room temperature $\left(22^{\circ} \mathrm{C}\right.$ ) in $150 \mathrm{mM}$ PBS buffer ( $\left.\mathrm{pH} 7.4\right)$ containing lysozyme $(2 \mathrm{mg} / \mathrm{mL})$, followed by 2 years storage at $4{ }^{\circ} \mathrm{C}$. Hydrogel samples were briefly rinsed in PBS to remove unbound material before being placed on pre-chilled SEM metal stubs.

\section{RESULTS AND DISCUSSION}




\subsection{Effect of lysozyme on physicochemical properties of HEA-HEMA hydrogels loaded with lysozyme}

\subsubsection{HEA-HEMA hydrogels swelling in the presence of lysozyme in buffer solution}

The equilibrium swelling degrees of HEA-HEMA hydrogels (with and without lysozyme) as a function of the HEA content in polymeric network are presented in Fig. 1 (a). For both samples the equilibrium swelling degree depends strongly on the ratio between co-monomers (HEA and HEMA) in the hydrogel network and reveals non-linear behaviour. A moderate increase in the swelling degree occurs for hydrogel compositions with HEA $\leq 40 \mathrm{~mol} \%$, whereas the HEA-rich samples (HEA $\geq 70 \mathrm{~mol} \%$ ) show the most significant increase in the equilibrium swelling degree (around $1300 \%$ ), thus imbibing 7-10 times more liquid than HEMA-rich hydrogels.

Generally, variation in the swelling degree is related both to the difference in the hydrophobicity of HEA and HEMA monomers (as a more hydrophilic monomeric unit lacking extra methyl group, HEA is able to attract more water favouring the osmotic water diffusion into the hydrogel matrix) and the mesh size of the polymeric network (i.e. distance between the cross-links) obtained during hydrogel synthesis. As it was estimated previously [16], the molecular weight between the crosslinks in HEA-HEMA hydrogels varied from 270g/M (i.e. 2 monomers) for Poly-HEMA to 50,000 g/M for Poly-HEA (i.e 435 monomers).

Results shown in Fig. 1 (a) also reveal that the general character of HEA-HEMA hydrogels swelling in aqueous $[16,17]$ and in buffered solutions with or without protein is similar with only a minor decrease in the swelling degree for the hydrogels swollen in the presence of lysozyme. Thus, the swelling degree of the hydrogels is determined mainly by the hydrogel composition.

The kinetics of the hydrogel swelling (Fig. 1 (a, insert), only examples for HEA50 and HEA 80 are shown) in buffered solutions containing lysozyme shows that more hydrophilic HEA-rich hydrogels (HEA content $80 \mathrm{~mol} \%$ ) reach the swelling equilibrium faster. To elucidate the mechanism of fluid diffusion into the polymer matrix during hydrogel swelling in protein solution, the diffusion exponents $n$ were estimated using Ritger-Peppas equation [28]:

$$
\frac{M_{t}}{M_{0}}=k t^{n}
$$


where $\mathrm{M}_{\mathrm{t}}$ and $\mathrm{M}_{0}$ are the amount of water absorbed by the hydrogel at time $t$ and at equilibrium, respectively, $k$ is a characteristic constant of the system and $n$ is a characteristic exponent of the mode of water transport [1]. The value of the diffusion exponent $n$ has been shown to be dependent on the rates of liquid diffusion into the polymer matrix and polymer relaxation $[1,29,30]$. If $n=0.5$ the case corresponds to the Fickian diffusion-controlled mechanism (where the rate of water diffusion is lower than the rate of relaxation of the polymer chain); if $0.50<n<1$, the non-Fickian diffusion takes place (when the water diffusion and chain relaxation rates are comparable); if $n<0.5$, the case is regarded as Fickian diffusion (but "less Fickian" when the water penetration rate is much below the polymer chain relaxation rate [31]).

Re-writing equation (3) in a form

$$
\ln \frac{M_{t}}{M_{0}}=\ln \boldsymbol{k}+\boldsymbol{n} \ln t
$$

allows estimating the coefficient $n$ from the swelling kinetics curves re-plotted in logarithmic coordinates $\ln \left(\mathrm{M}_{\mathrm{t}} / \mathrm{M}_{0}\right)$ vs. $\ln (\mathrm{t})$. Initial parts of the $\ln \left(\mathrm{M}_{\mathrm{t}} / \mathrm{M}_{0}\right)$ vs. $\ln (\mathrm{t})$ dependencies (where the swelling fraction $\mathrm{M}_{\mathrm{t}} / \mathrm{M}_{0} \leq 0.6$ ) were fitted with linear function and the gradient values corresponding to the diffusion exponent $n$ according to Eq. (4)) were plotted against the HEA content (Fig. 1 (b)). As is seen, HEMA-rich samples (HEA $<70$ mol \%) revealed "less Fickian" type of diffusion of liquid into hydrogels ( $n$ in the range of $0.33-0.45$ ). HEA-rich hydrogels (HEA $>80 \mathrm{~mol} \%)$ show non-Fickian type of diffusion $(0.5<n<1)$ meaning that their swelling is a chain relaxation-controlled process (the water diffusion is much faster than the rate of relaxation). HEArich hydrogels can absorb water very quickly due to larger pores and hydrophilic nature of HEA whilst the hydrogels with higher proportions of HEMA are more hydrophobic in nature and more cross-linked; therefore, it takes longer to hydrate the polymer network and the swelling kinetics depends on the rate of water diffusion as well as on the polymer chain relaxation rate.

The comparison of the swelling mechanisms in aqueous and in protein solutions also confirmed that hydrogel swelling is identified mainly by the monomer composition even in the presence of protein in liquid phase. The equilibrium swelling degree is slightly reduced in the presence of protein. 


\subsubsection{Morphology of HEA-HEMA hydrogels in buffered solutions containing lysozyme}

The internal structure of HEA-HEMA hydrogels fully swollen in PBS buffer containing lysozyme was examined using SEM (Fig. 2 (a-d)). Analysis of the SEM micrographs of hydrogels reveals that in buffered solution containing lysozyme all hydrogels have a porous structure which is highly dependent on the HEA content in the copolymer. PHEMA hydrogels are rather dense with thick polymer "walls" $(10-50 \mu \mathrm{m})$ and a number of poorly interconnected large pores $(15-35 \mu \mathrm{m})$. As the HEA content increases, the structure of the hydrogels changes becoming significantly more porous; as a result the pore sizes (5 - $10 \mu \mathrm{m}$ for HEA70) and the thickness of the polymer "walls" $(0.5-1 \mu \mathrm{m}$ for HEA70) decrease. In the case of HEA-rich hydrogels their pores are highly interconnected and occupy the majority (> 80-90\%) of the image area. The increased porosity of the HEA-rich hydrogels is in line with the increased swelling degree (i.e. water sorption capability) of these hydrogels (Fig. 1 (a)). These structural changes are related to the increased interaction between more hydrophilic HEA fragments and water molecules. Similar results were obtained for the protein-free hydrogels [17]. Thus, comparison of hydrogel porous structures formed in water and in lysozyme solution shows that the morphology of the HEA-HEMA hydrogel is mostly defined by the copolymer composition whereas the presence of a protein in a swelling medium can only have a minute effect on the hydrogel internal structure.

\subsubsection{Effect of lysozyme on the total amount of liquid phase in fully swollen HEA-HEMA hydrogels}

The addition of large molecules (proteins) can adversely affect the physicochemical properties of hydrogels including the total water content. Thermogravimetric analysis was used to determine the total water content in fully swollen hydrogels with different HEA content loaded with lysozyme. Fig. 3 (a) shows typical TGA thermograms illustrating the hydrogel weight loss with temperature due to water evaporation from the samples. The dependencies of the total water content on HEA concentration in hydrogels are shown in Fig. 3 (b). The results obtained are in agreement with the results on the swelling degree (Fig. 1 (a)): as the HEA content increases, the total amount of water imbibed by the hydrogels increases substantially. PHEMA and HEMA-rich samples contain 55-60\% of liquid phase, whilst HEA-rich samples (HEA $\geq 80$ ) contain about $90 \%$ of water. The presence of lysozyme has a very little impact on the amount of liquid, which hydrogels can imbibe (Fig. 3 (b), curves 1 and 3) confirming that in buffered solutions containing the protein the swelling degree (and 
the amount of the liquid phase) of the HEA-HEMA hydrogels is determined by the co-polymer composition regardless of the loaded macromolecules.

\subsubsection{Effect of lysozyme on water retention properties by HEA-HEMA hydrogels}

To study the effect of lysozyme on the hydrogel water retention properties, the weight loss upon incubation of swollen hydrogels at physiological temperature $\left(37^{\circ} \mathrm{C}\right)$ was monitored using TGA ("loss-on-drying”). After $120 \mathrm{~min}$ incubation, hydrogels were heated to $250{ }^{\circ} \mathrm{C}$ to evaporate residual liquid remained after incubation at $37{ }^{\circ} \mathrm{C}$. Prior to the measurements, hydrogels were fully equilibrated either in PBS buffer or in PBS buffer containing lysozyme.

Fig. 4 (a) presents typical 'loss-on-drying' TGA weight vs. time curves for different hydrogels loaded with lysozyme. Weight of a hydrogel sample decreases upon incubation at constant temperature due to water expelling from hydrogel. As is seen, the HEA-rich hydrogels lose almost $100 \%$ liquid during 120 -min incubation at $37{ }^{\circ} \mathrm{C}$ and further increase in temperature (from 37 to $250{ }^{\circ} \mathrm{C}$ between 120 and $160 \mathrm{~min}$ ) causes no change in sample weight (Fig. 4 (a)). The HEMA-rich hydrogels retain some amount of liquid ( 10-15\%) after $37{ }^{\circ} \mathrm{C}$ incubation (Fig. 4 (b)), which is evaporated at following temperature increase from 37 to $250{ }^{\circ} \mathrm{C}(120-160$ min time interval $)$. Loading with lysozyme has very little impact on the general profiles of water evaporation from the hydrogels (Fig. 4(b), curves 1 and 2). Increase of lysozyme concentration up to $30 \mathrm{mg} / \mathrm{mL}$ slightly decreases the \%water loss for HEMA-rich samples and negligibly increases for HEMA50 (Fig. 4b, insert).

The effect of the lysozyme concentration in the swelling medium on the water loss was investigated using hydrogel samples incubated in lysozyme solutions at $4{ }^{\circ} \mathrm{C}$ for at least 5 weeks before the measurements (Fig. 4 (b, insert)). The results show that the PHEMA and HEMA-rich hydrogels $($ HEA $\leq 30 \mathrm{~mol} \%)$ loaded with high concentrations of lysozyme retain slightly $(2-4 \%)$ more water than protein-free samples. As for the HEA-rich hydrogels (HEA $\geq 50 \mathrm{~mol} \%$ ) there are no significant differences in the water retention regardless of the lysozyme concentration in solution.

The water evaporation profiles (Fig. 4(a)) show "fast" (initial) and "slow" (subsequent) evaporation stages with an "inflection" point (estimated as illustrated in Fig. 4 (a, insert)) separating the stages. It is assumed that easily accessible and weakly interacting (or not interacting) with polymer matrix 
water (i.e. bulk water) is evaporated during the "fast" stage, while bound water is evaporated during the "slow" stage [17]. The duration of the fast stage and the amount of fast evaporating water strongly depend on HEA content and increase in the case of HEA-rich hydrogels (Fig. 4 (a), (c)) for both loaded with lysozyme and protein-free samples. The results obtained clearly correlate with the swelling degree of the hydrogels with different HEA content (Fig. 1); the higher the swelling degree is and the more water hydrogels can imbibe, the greater the percentage of the fast evaporating water (bulk water) in hydrogels is and the longer time is required to evaporate it.

\subsubsection{DSC analysis of the thermal properties of water in HEA-HEMA hydrogels swollen in the presence of lysozyme}

The thermal behaviour of water absorbed by the hydrogels was studied using DSC. Typical DSC thermograms illustrating crystallization (at cooling from 30 to $-40^{\circ} \mathrm{C}$ ) and subsequent melting (at heating from -40 to $30{ }^{\circ} \mathrm{C}$ ) of water in hydrogel samples fully swollen in buffered solutions containing lysozyme are shown in Fig. 5(a). For all hydrogel samples the sharp exothermic crystallization peak and broad endothermic melting peak were observed. It is well known, that the total water in hydrogels can be divided into "freezing" and "non-freezing" water, where "nonfreezing" is related to bound water and "freezing" is associated with free (bulk) water and freezing interfacial water [32]. Only the freezing water is responsible for the crystallization and melting peaks present in DSC thermograms. Being more hydrophilic, HEA-rich hydrogels imbibe more liquid and, therefore, contain more liquid per one unit of hydrogel weight and, consequently, more free (freezing) water. As a result, the melting enthalpies increase with HEA content in hydrogels (Fig. 5 (b)).

Diffusion of solutes through a hydrogel network depends not only on the total water content but also on the binding state of water varying for free and bound water. The combination of DSC-TGA methods allows estimating the amount of free and bound water in hydrogels [17] and the effect of lysozyme on the redistribution of different types of water. The total amount of water (freezing and non-freezing) in hydrogels measured using TGA (Fig. 3) can be represented as a summary of freezing and non-freezing water:

$$
W_{\text {total }}(\%)=W_{\text {bound }}(\%)+\left(\frac{\Delta H_{\text {freezing }}}{\Delta H_{\text {pure }}} \times 100 \%\right)
$$


where $W_{\text {total }}$ and $W_{\text {bound }}$ are the amounts of total and non-freezing water in hydrogels equilibrated in lysozyme solution, $\Delta H_{\text {freezing }}$ is the melting enthalpy of freezing water (Fig. 5 (b)), $\Delta H_{\text {pure }}$ is the melting enthalpy of pure water, $334 \mathrm{~J} \mathrm{~g}^{-1}$ [33].

The percentage of freezing water in HEA-HEMA hydrogels increases with HEA content both for lysozyme-loaded and protein-free hydrogels (Fig. 6). The strongest gain in the amount of freezing water was observed when HEA content rises from 30 to $40 \mathrm{~mol} \%$, which is in agreement with the swelling data (Fig. 1 (a)). Loading with lysozyme reduces the amount of freezing water as some water molecules are bound to the protein molecules. However, as the results in Fig. 6 show, lysozyme has a minor effect on the free/bound water redistribution across the hydrogels with different HEA content. It should be noted that the total amount of water is determined by both polymer composition and cross-linking properties (i.e. mesh size), whereas the proportion of nonfreezing and freezing water is mainly dictated by the ratio of hydrophobic and hydrophilic monomers, i.e. hydrogel composition.

\subsubsection{In vitro loading of lysozyme into and release of lysozyme from HEA-HEMA hydrogels}

The lysozyme loading capacity and the rate of loading for HEA-HEMA hydrogels with low and high HEA contents were assessed by placing the swollen hydrogel samples into a buffered protein solution for a fixed period of time followed by placing the fragments into a fresh buffer and measuring the concentration of protein released. The lysozyme concentration was then recalculated for the amount of liquid in hydrogels (Fig. 3 (b)) to estimate the lysozyme concentration inside the samples. Fig. 7 (a) shows that HEMA-rich hydrogels upload lysozyme rather slowly as after 24 hours of incubation in lysozyme solution, the lysozyme concentration in PHEMA was below 10\% of the lysozyme concentration in solution used to incubate the hydrogels and ascribed to $100 \%$. In contrast, the lysozyme concentration in HEA80 is more than $90 \%$ of the lysozyme concentration in the incubation solution after 24 hours. After 12 days the lysozyme concentrations inside all hydrogels were very close to the lysozyme concentration in the solution (Fig. 7 (a)).

As controlled drug release systems, hydrogels are supposed to deliver a drug at a specific rate; therefore kinetics of the macromolecules (i.e. protein) release from hydrogels is one of the most important characteristics. In vitro release of lysozyme from the hydrogels fully equilibrated in buffered lysozyme solution was studied under conditions simulating the physiological environment. 
In a typical experiment a hydrogel sample was placed in fresh buffer solution and protein release over time was monitored spectrophotometrically at $280 \mathrm{~nm}$. Fig. 7 (b) shows the typical cumulative release profiles illustrating lysozyme release from the hydrogels with different HEA content. In the case of HEA-rich hydrogels the release profiles for lysozyme show an initial "burst effect". A comparison of 70\%- lysozyme release times across the range of HEA-HEMA hydrogel formulations (Fig. 7 (c)) shows that the rate of protein release is highly influenced by the composition of the hydrogels and remarkably increases with a growth in HEA content. HEA-rich samples (HEA70, HEA80) release $70 \%$ of total pre-loaded lysozyme in less than 30-40 min, whilst PHEMA and HEMA-rich samples (HEA $<40 \mathrm{~mol} \%$ ) release $70 \%$ of the lysozyme after more than 3-5 hours. The greater release rates in the case of HEA-rich hydrogels are due to significantly higher swelling degree (Fig. 1 (a)) and a wide network of interconnecting pores (see Fig. 2) facilitating diffusion of the protein molecules. These results are in agreement with the theoretical model of diffusion stating that the reduction in the area available for transport of the molecules proportionally reduces the diffusion coefficient of solute within the polymer matrix [34].

The results obtained show that, depending on the application, the co-polymer composition of HEAHEMA hydrogels can be adjusted to achieve the desired drug release rate, i.e. fast or sustained release behaviour.

Loading into and releasing from hydrogels can cause stress to the protein molecules possibly resulting in alteration in their native structure and, consequently, in protein unfolding and aggregation. To be considered as a potential carrier for large macromolecules, hydrogels should not compromise the conformation and activity of proteins carried. UV-spectroscopy and FTIR were used to characterise the secondary structure of lysozyme released from HEA-HEMA hydrogels with different HEA content.

Lysozyme released from HEA-rich hydrogels (HEA $\geq 70 \mathrm{~mol} \%$ ) has UV spectra typical for native proteins with a peak near $280 \mathrm{~nm}$, a characteristic shoulder at $290 \mathrm{~nm}$, and no absorbance above 310 $\mathrm{nm}$. The latter evidences that no protein aggregates are formed in solution. The ratios between absorbances at 260 and $280 \mathrm{~nm}\left(\mathrm{~A}_{260} / \mathrm{A}_{280}\right)$ in the UV spectra were 0.6 for untreated lysozyme (which is typical for native proteins [35]) and $0.605 \pm 0.003$ for lysozyme released from HEA70HEA90 hydrogels. UV spectra of lysozyme released from HEMA-rich hydrogels (HEA $\leq 60$ mol\%) 
were also close to the UV spectrum of native lysozyme with no absorbance at wavelengths above $310 \mathrm{~nm}$ (and hence no aggregation). However, in this case the values of $\mathrm{A}_{260} / \mathrm{A}_{280}$ were in the $0.65-$ 0.675 range meaning that the minute alterations to the secondary structure of the protein could occur. To make these minor alterations more pronounced, an additional stress has been applied to proteins: lysozyme at relatively low concentration (which was kept the same for all samples) in aqueous solution, after being released from hydrogels with different HEA content, was processed via lyophilisation without cryo- or lyo-protectants. It is known that freeze-drying can cause irreversible damage to proteins, especially if freeze-dried formulation does not include protein stabilizers (for instance, polymers and/or sugars, buffering salts, etc.) [36, 37]. As a control, a freshly prepared lysozyme aqueous solution was freeze-dried. The secondary structure of lyophilised lysozyme was analysed using ATR-FTIR spectroscopy.

FTIR is a powerful technique to study structure of proteins, including lysozyme [38]. A typical IR spectrum of a protein contains two major bands originated from the peptide groups - amide I and amide II bands. The amide I (between 1600 and $1700 \mathrm{~cm}^{-1}$ ) is the most intense absorption band and mainly associated with the stretching vibration of the $\mathrm{C}=\mathrm{O}(70-85 \%)$ and $\mathrm{C}-\mathrm{N}(10-20 \%)$ groups. The exact frequency of the amide I band is determined by the backbone conformation and the hydrogen bonding pattern [39, 40]. Amide II band (in the 1510 and $1580 \mathrm{~cm}^{-1}$ region) results from the in-plane $\mathrm{N}-\mathrm{H}$ bending vibration (40-60\%) and from the $\mathrm{C}-\mathrm{N}(18-40 \%)$ and the $\mathrm{C}-\mathrm{C}$ (about 10\%) stretching vibration. This band is sensitive to the protein conformation. To analyse (and even predict) the protein secondary structure the amide III region $\left(1220-1330 \mathrm{~cm}^{-1}\right.$, in-phase combination of the $\mathrm{N}$ $\mathrm{H}$ bending and the $\mathrm{C}-\mathrm{N}$ stretching vibrations with small contribution from the $\mathrm{C}-\mathrm{O}$ in-plane bending and the $\mathrm{C}-\mathrm{C}$ stretching vibration) is also used despite the complicity due to side chain contribution to the mode [39 and refs. 166-169 therein]. Amide III mode can be analysed almost without spectral deconvolution as the bands of different secondary structures are separated ( $\alpha$-helix 1293-1328, $\beta$ sheet $1225-1250$, other $-1257-1288 \mathrm{~cm}^{-1}$ [41]; besides, the absorbance of water is negligible in this region.

The FTIR spectrum of untreated freeze-dried lysozyme (Fig. 8, top curve) shows two strong amide I and II bands at around 1649 and $1535 \mathrm{~cm}^{-1}$, respectively (Table 1). The FTIR spectra of lysozyme released from PHEA and HEA-rich hydrogels (HEA100, HEA80 and HEA70) show only minor shifts of the amide I and II band maxima towards higher wavelengths (1652 and $1539 \mathrm{~cm}^{-1}$, Fig. 8). 
FTIR spectra of freeze-dried lysozyme released from HEMA-rich hydrogels (HEA30 and HEA50) reveal more significant spectral alterations - further shifts of the amide I and II bands and decrease in their relative intensities. The magnitude of the structural changes clearly correlates with the HEA content in hydrogels, i.e. changes in the IR spectra are more pronounced in the case of lysozyme released from HEMA-rich hydrogels. It was previously shown that the lyophilisation-induced alterations in the conformation-sensitive amide I region are not a result of water removal from the proteins but due to protein unfolding [40]. Overall, the structural changes occurring in the amide I and II bands upon lyophilisation of lysozyme released from hydrogels with different HEA content, in addition to the minor changes in UV-spectra, evidence some difference between the secondary structures of native lysozyme and lysozyme released from HEMA-rich hydrogels. Protein released from those hydrogels shows signs of secondary structure alterations amplified as a result of the stress applied (freeze-drying in low concentration aqueous solution without protectants). The latter confirms a minor damage to the native secondary structure of lysozyme released from HEMA-rich hydrogels.

Summarising the first part of our feasibility study, we have to emphasize that relatively stable protein (lysozyme) was selected to understand the effect of the protein on the properties of hydrogels. In the future research it would be interesting to study less stable proteins which can be used for specific therapeutic applications of the hydrogel drug delivery systems.

\subsection{Protein aggregation and deposition onto HEA-HEMA hydrogels}

\subsubsection{Lysozyme deposition on HEA-HEMA hydrogels}

As it was mentioned above, the long-term contact between hydrogels and proteins can lead to protein deposition on hydrogels, the extent of which is shown to be dependent on the time of exposure [42]. To study protein deposition on HEA-HEMA hydrogels, the hydrogel samples (HEA $0,30,40,50,70$ and $80 \mathrm{~mol} \%$ ) were immersed in aqueous or buffered solutions containing lysozyme $(2 \mathrm{mg} / \mathrm{mL})$. After 1.5 months of storage at $22{ }^{\circ} \mathrm{C}$, the protein deposition on HEMA-rich and HEA-rich hydrogels was assessed using SEM. A small amount of separated protein plagues (around 3-10 $\mu \mathrm{m}$ ) was found on PHEMA and HEMA-rich $(30,40,50)$ hydrogel samples (Fig. 9 (a)). HEA70 and 80 samples contained only a few small (about 1-6 $\mu \mathrm{m}$ ) protein plagues (Fig. 9 (b)). The

results show that after 1.5 month at room temperature lysozyme forms separated deposits on 
PHEMA and HEA-HEMA hydrogels; however, the amount of the deposits is relatively low on HEMA-rich hydrogels and even less on HEA-rich hydrogels.

The amount of lysozyme loaded into hydrogels after prolonged (1.5 months) incubation of hydrogels in the lysozyme solutions with different protein concentrations was measured as described above (sections 2.2.6 and 3.1.6). During incubation all samples were kept at $4{ }^{\circ} \mathrm{C}$ to minimize protein aggregation. For all hydrogels tested the calculated concentrations of lysozyme inside the hydrogels were well above the concentration in an incubation solution (i.e. > 100\%) (Fig. 10). In the case of HEA-rich hydrogels these concentrations were in the range of 150-180\%. More hydrophobic HEMA-rich hydrogels absorb significantly more protein (above $200 \%$ ) regardless of the initial lysozyme concentration in solution. The excessive loading evidences that lysozyme not only loaded into but also accumulated by hydrogels in the case of long-term incubation.

Long-term (1 year) incubation of samples in lysozyme solution even at low temperature $\left(4{ }^{\circ} \mathrm{C}\right)$ results in massive protein deposition on the hydrogels (Fig. 9 (c - e)). In this case proteins form a "network" of plagues on the surface and inside the polymer matrix. It is of interest to note, that for all samples (except PHEMA) the areas enriched in protein deposits adjoin the area without protein deposits (Fig. 9 (c - e)). Similar to the short-term study, after long incubation in lysozyme solution the average amount of protein plagues on HEA-rich hydrogel (HEA80) is seems to be less than on HEMA-rich hydrogel (PHEMA and HEA10).

It has been shown previously, that protein deposition on contact lenses is strongly dependent on the lens material [21 and references therein]. Materials primary consisting of PHEMA are categorised as Group I materials (non-ionic, < 50\% water) by the FDA [21] and characterised as low deposition level materials. Nevertheless, protein adsorption on the PHEMA-based lenses was found after just 1 minute contact with tears [20,43]; after 2 hours of wearing the protein surface coating on PHEMA lenses was determined as $\sim 10-30 \mathrm{ng} / \mathrm{cm}^{2}$ [44]. Incorporation of some materials (for instance, hyaluronic acid) into PHEMA can significantly reduce the degree of protein deposition [45, 46]; at the same time other hydrophilic negatively charged monomers (for instance, methacrylic acid, MAA) are known to result in significant increase in the amount of deposited lysozyme [47]. Our results show that the inclusion of HEA (non-ionic as well as HEMA) into pHEMA matrix increases the resistance of hydrogels to protein deposition. Proteins have been shown to express a higher 
affinity for hydrophobic surfaces than hydrophilic [19], as in this case the entropic gain (due to protein dehydration) forces protein adsorption at the surface. In its swollen state PHEMA has been shown as being hydrophilic with some hydrophobic properties [48]; thus hydrophobic interaction between lysozyme and non-polar parts of PHEMA structure is favourable. As a more hydrophilic co-polymer lacking one methyl group, HEA is expected to reduce protein absorption onto hydrogel surface what was observed in our experiments (Fig. 9). However these preliminary results require additional experimental support, which is outside of the scope of the present work.

\subsubsection{Effect of lysozyme deposition on the mechanical properties of HEA-HEMA hydrogels}

The mechanical properties of HEA-HEMA hydrogels fully swollen in PBS buffer without or with lysozyme were studied using Texture Analysis. The hydrogel samples were incubated in buffered protein solution containing a physiological concentration of lysozyme for a sufficiently long time ( 2 months) to allow some protein deposition on hydrogels (as confirmed by SEM). The data show that an increase in HEA content results in significant decrease in stress meaning that HEA-rich hydrogels are significantly softer than PHEMA and HEMA-rich co-polymer hydrogels and much less force is required to deform HEA-rich hydrogels (Fig. S1, a). Even small addition of HEA (10 mol \%) leads to almost 2-times decrease in stress required to compress a hydrogel sample. Loading hydrogels with lysozyme and lysozyme deposition onto hydrogels has no significant impact on the HEA-HEMA hydrogel mechanical properties (Fig. S1, b).

\subsubsection{Aggregation of lysozyme in solution in the presence of HEA-HEMA hydrogels}

It is known that protein unfolding and aggregation can be induced or catalysed by many external factors. Contact with hydrogel surface and mechanical stress during loading/release can potentially disturb the protein native conformation and facilitate the aggregation. To assess the effect of HEAHEMA hydrogels on the protein aggregation, the hydrogel samples were incubated in solutions containing lysozyme at room temperature. Lysozyme aggregation in time was analysed and quantified using turbidimetry at $360 \mathrm{~nm}$ assay, ThT assay, SEM and light microscopy.

Fig. 11 shows the values of optical density at $360 \mathrm{~nm}\left(\mathrm{OD}_{360}\right)$ for lysozyme solutions incubated in the presence of different HEA-HEMA hydrogels. As a control, the aggregation of lysozyme in the buffer solution without hydrogels was used. As expected, prolonged incubation of lysozyme in 
solution causes an increase in the optical density at $360 \mathrm{~nm}$ for all samples due to protein aggregation. However, the increase in $\mathrm{OD}_{360}$ is more pronounced in the presence of HEMA-rich hydrogels (Fig. 11). As the turbidimetry assay being based on the total amount of scattering particles is a non-specific method and the results can be compromised by the presence of small hydrogel fragments in solution, Thioflavin T (ThT) assay was performed to attribute the increase in the optical density at $360 \mathrm{~nm}$ to protein aggregation. It is known that ThT fluorescence emission is increased substantially in the presence of protein amyloids/aggregates but not in the presence of natively folded proteins or small hydrogel fragments in solution [49]. Our results from the ThT assay confirms the presence of lysozyme aggregates in all solutions tested (data not shown) as the increase in ThT fluorescence emission observed was correlated with the increase in $\mathrm{OD}_{360}$. The lysozyme aggregation is found to be irreversible (data not shown). The presence of protein aggregates was also detected using scanning electron and light microscopy.

Overall, the data obtained show that the irreversible lysozyme aggregation occurs as a result of prolonged incubation of lysozyme in solution. Protein aggregation increases in the presence of hydrogels with low and intermediate HEA content (HEA < 60 mol \%), whilst HEA-rich hydrogels $(\mathrm{HEA} \geq 70 \mathrm{~mol} \%$ ) have little or no effect on the degree of lysozyme aggregation in solution.

As it is mentioned earlier, proteins are able to absorb to the surfaces and show higher affinities for hydrophobic surfaces than hydrophilic. Proteins deposited on hydrogels exhibit conformational changes that may result in protein destabilization and denaturation [50,51]. For instance, it was shown that albumin binds irreversibly and denatures within one hour of exposure to hydrogels [51]. More favourable interaction with more hydrophobic hydrogels means that lysozyme interaction and, as a result, its denaturation and aggregation is going more intensively in the presence of HEMA-rich hydrogels. Besides, the enlarged interconnected network of pores formed in HEA-rich hydrogels (Fig. 2) favours protein migration/diffusion inside the hydrogels and reduces the damaging stress thus impacting the stability of loaded and deposited proteins. This conclusion is supported by our results on lysozyme loading into the hydrogels with different HEA content showed above (Fig. 10) which evidence the increased absorption of lysozyme by HEMA-rich hydrogels. We also have shown that lysozyme released from HEMA-rich hydrogels is (to some extent) destabilised and can be damaged and aggregated if an additional stress is applied (see Fig. 8). 


\section{CONCLUSIONS}

In the present work the interaction of HEA-HEMA hydrogels with a model small protein (lysozyme) was studied to assess the potential applications of these hydrogels as a drug delivery system for sustained release of protein therapeutics. Our results show that copolymerisation of HEMA and HEA monomers allows controlling the physicochemical properties of hydrogels (equilibrium swelling degree, morphology, mechanical strength, water retention and the rate of therapeutic agent release) while loading with protein has very little impact on these properties. An increase in effective pore network due to more hydrophilic HEA introduction promotes diffusive penetration of lysozyme and increases protein loading rate. Varying the HEA-HEMA hydrogel composition, a desirable protein release time can be achieved. The HEMA-rich hydrogels are more suitable for sustained release drug, but have an impact on the proteins stability in the case of long-term incubation. Proteins released from hydrogels with intermediate and high HEA content preserve their native conformation. Additionally, the drug release time can also be regulated by modification of the swelling medium, i.e. using more viscous liquid (e.g. water-glycerol/PEG solutions) to get slower diffusion of drug from the hydrogel. For biological macromolecules (proteins) this approach is not always straightforward as glycerol and PEG are able to alter the protein activity; however, in the case of many proteins (according to the published data) these solvents can be added to the medium without compromising the proteins. An advantage of the co-polymer hydrogel is that it can be designed with the optimal composition of monomers to achieve the desirable drug release with no effect on the protein.

Introducing HEA into the hydrogel matrix can also slightly decrease the lysozyme deposition on hydrogels. After both short- and long-term incubations, the level of lysozyme deposition on more hydrophobic HEMA-rich hydrogels was higher than on hydrophilic HEA-rich hydrogels. Overall, our feasibility study shows that HEA-HEMA hydrogels can potentially be used as a drug delivery system for large biopharmaceuticals (including proteins) as even low addition of the HEA copolymer can significantly increase the amount of imbibed protein and at the same time considerably reduce the unwanted protein deposition on the hydrogels.

\section{ACKNOWLEDGEMENTS}

The authors would like to thank Rachel Armitage (De Montfort University) for help with recording SEM images. 
Table 1. Amide I and Amide II bands maxima wavenumbers and relative intensities (strong, medium or weak) for freeze-dried lysozyme released from hydrogels with different HEA content.

\begin{tabular}{|l|l|l|}
\hline Lysozyme & Amide I band, $\mathbf{c m}^{-1}$ & Amide II band, $\mathbf{c m}^{-\mathbf{1}}$ \\
\hline untreated & 1649 strong & 1535 strong \\
\hline $\begin{array}{l}\text { Released from: } \\
\text { HEA30 }\end{array}$ & 1657 weak & 1543 weak \\
HEA50 & 1653 medium & 1539 medium \\
HEA70 & 1652 strong/medium & 1537 strong/medium \\
HEA80 & 1652 strong & 1539 strong \\
HEA90 & 1652 strong & 1537 strong \\
HEA100 & 1652 strong & 1535 strong \\
\hline
\end{tabular}




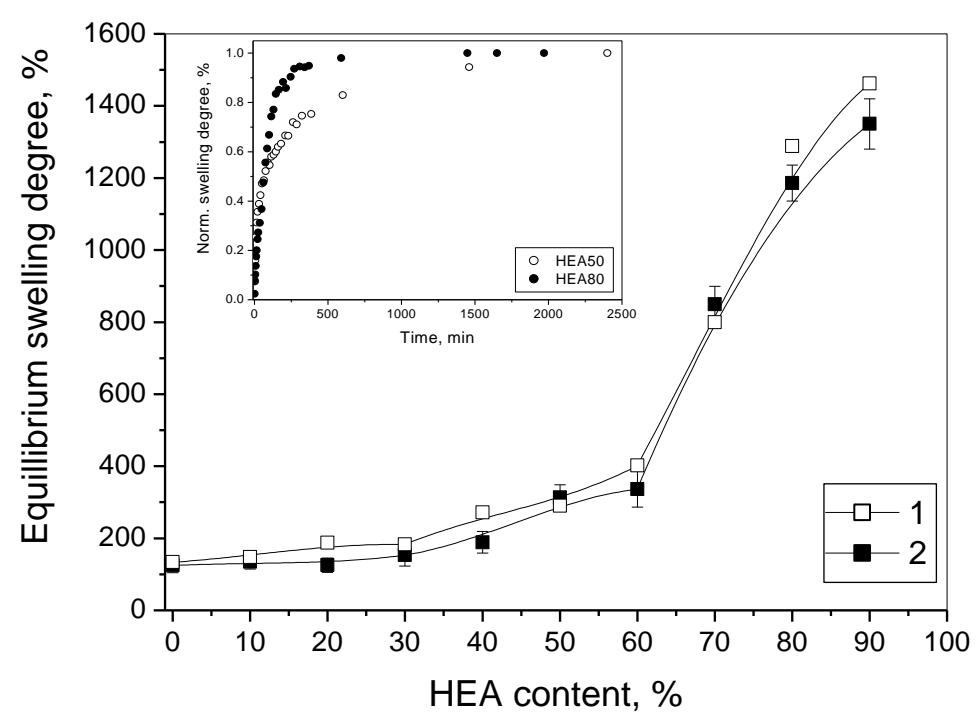

a)

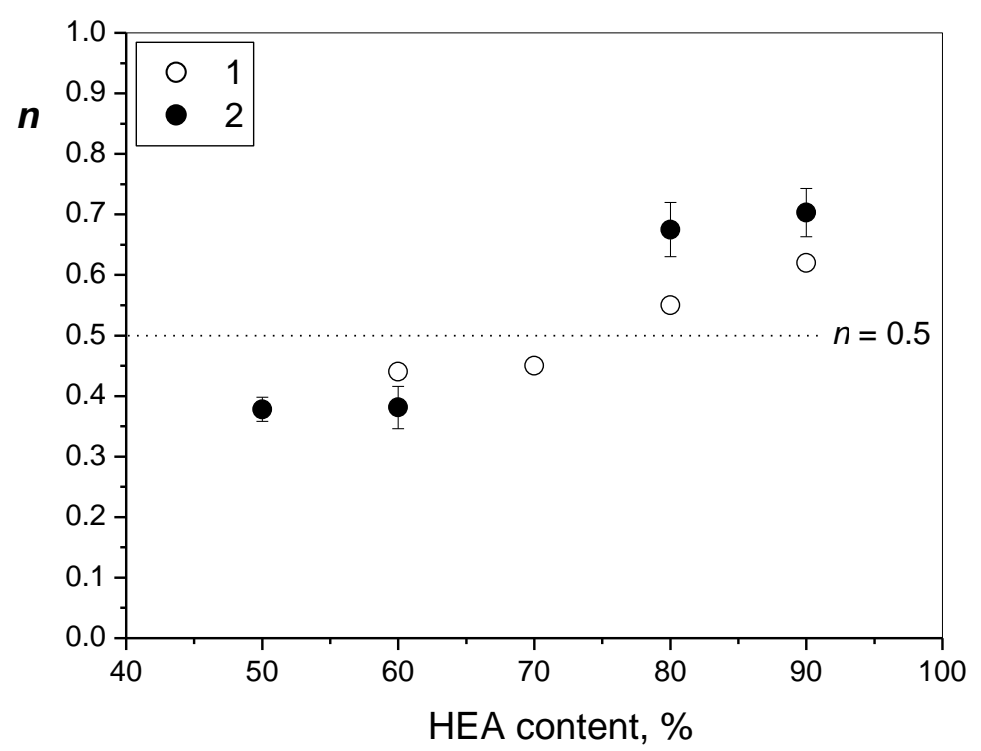

b)

Fig. 1. HEA-HEMA hydrogel swelling in aqueous and in buffer solutions containing lysozyme. (a). The equilibrium swelling degree as a function of the HEA co-polymer content for HEA-HEMA hydrogels fully swollen in aqueous solution (1) and in $150 \mathrm{mM}$ PBS buffer (pH 7.4) containing 10 $\mathrm{mg} / \mathrm{ml}$ lysozyme (2).

Insert: Typical swelling kinetics curves for HEA-HEMA hydrogels in PBS buffer containing lysozyme (curves for HEA50 and HEA80 samples are shown, dry sample weights $25 \pm 2 \mathrm{mg}$ ).

(b). Values of the diffusion exponent $n$ for hydrogels swelling in water (1, data from (Hackl et al., 2015)) and in PBS buffer containing lysozyme (2). 


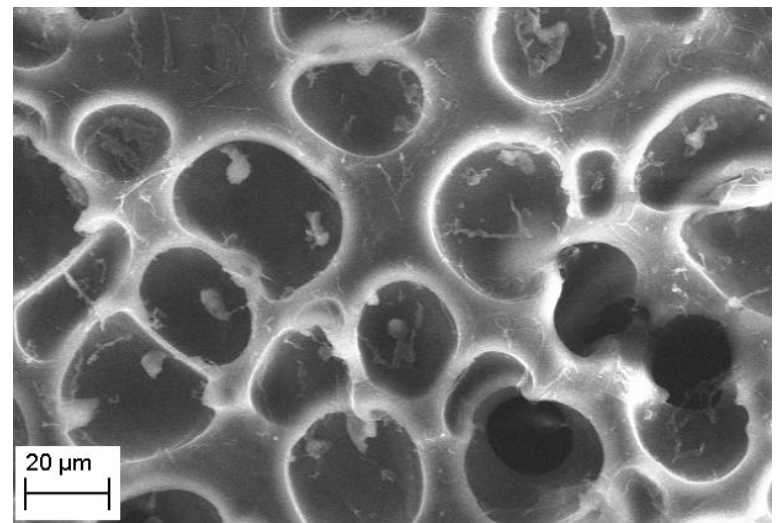

(a)

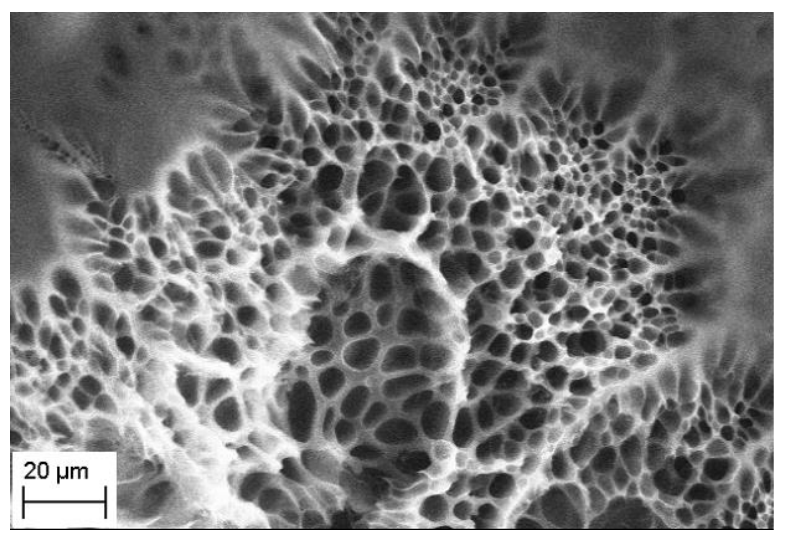

(c)

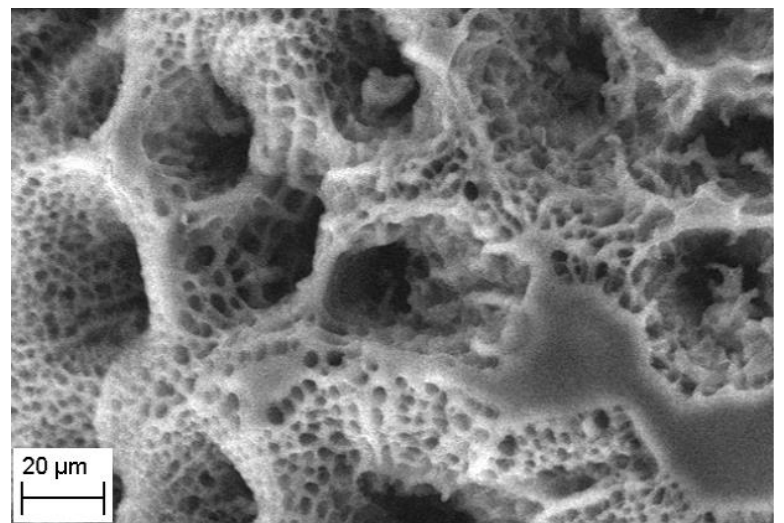

(b).

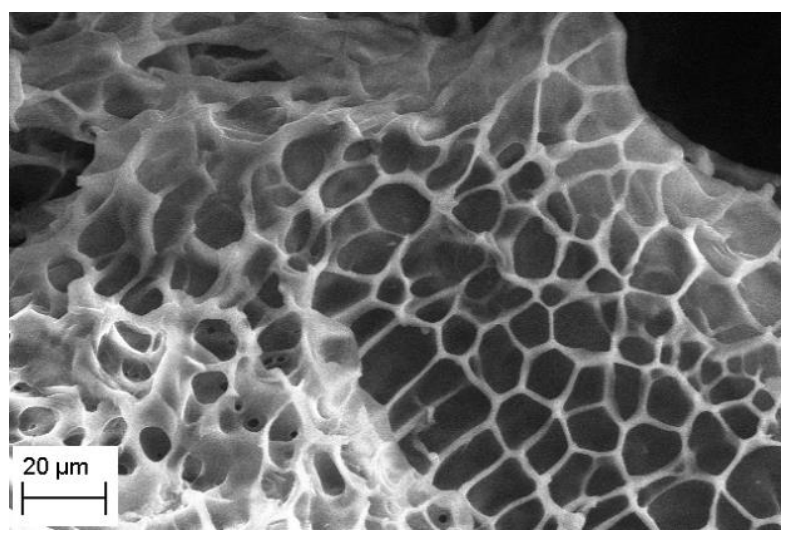

(d)

Fig. 2. SEM micrographs (x1000) of the porous structure of HEA-HEMA hydrogels equilibrated in $150 \mathrm{mM}$ PBS buffer containing lysozyme (10 mg/ml). HEA content, mol\%: (a) 0, (b) 30, (c) 50, (d) 70. 


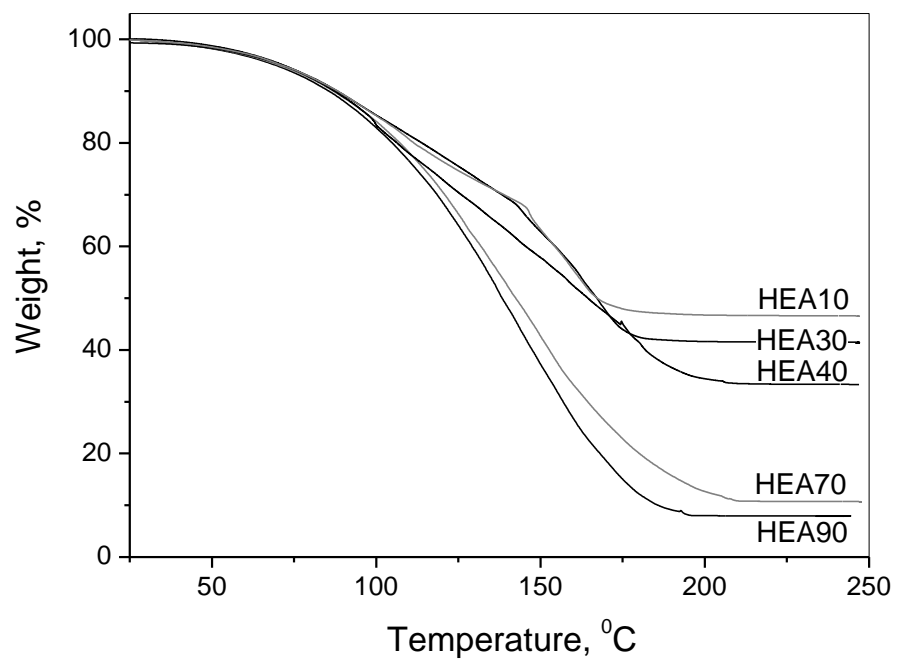

(a)

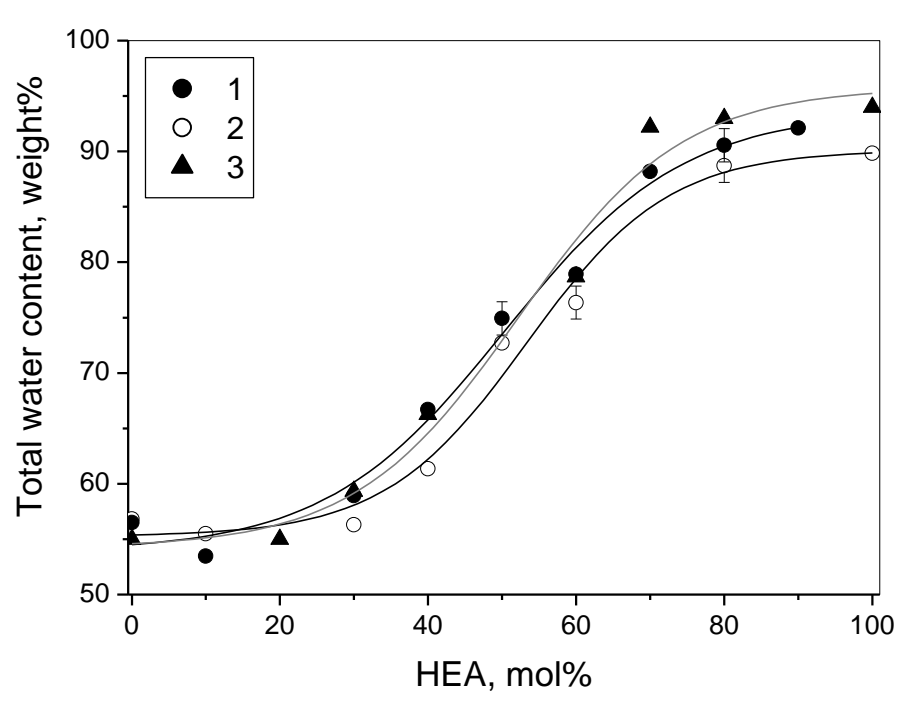

(b)

Fig. 3. TGA measurements of the total amount of liquid phase in HEA-HEMA hydrogels with different HEA content.

(a). Typical TGA thermograms of HEA-HEMA hydrogels loaded with lysozyme.

(b). Dependencies of the total amount of water in hydrogels on HEA content. Hydrogels were fully loaded with lysozyme $(1,2)$ in either buffered (1) solutions $(150 \mathrm{mM} \mathrm{PBS}, \mathrm{pH} 7.4,10 \mathrm{mg} / \mathrm{ml}$ lysozyme) or aqueous (2) solution ( $\mathrm{pH} 6,20 \mathrm{mg} / \mathrm{l}$ lysozyme) at $4^{\circ} \mathrm{C}$ during 2-3 weeks; (3) hydrogels were equilibrated in $150 \mathrm{mM}$ PBS buffer without lysozyme. Solid lines represent fitting of the experimental data to sigmoidal (Boltzmann) function using Origin Microcal software. 


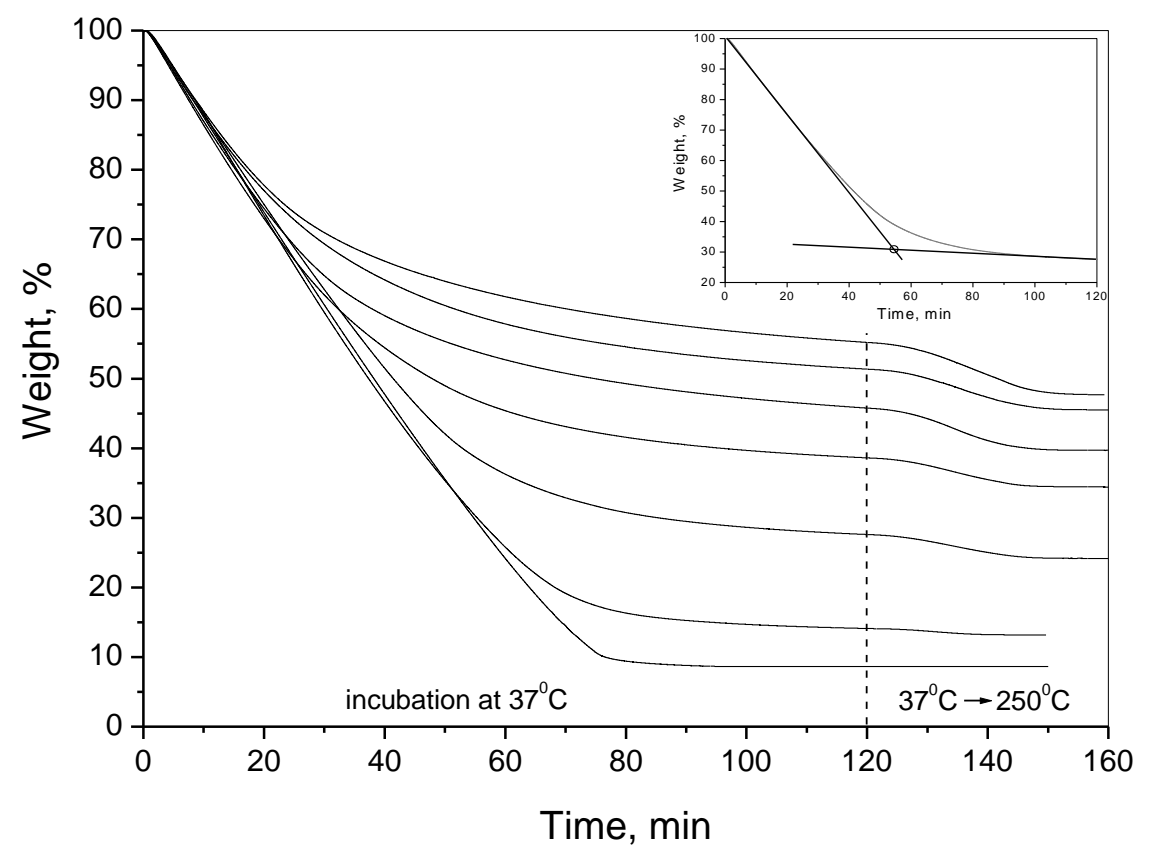

(a)

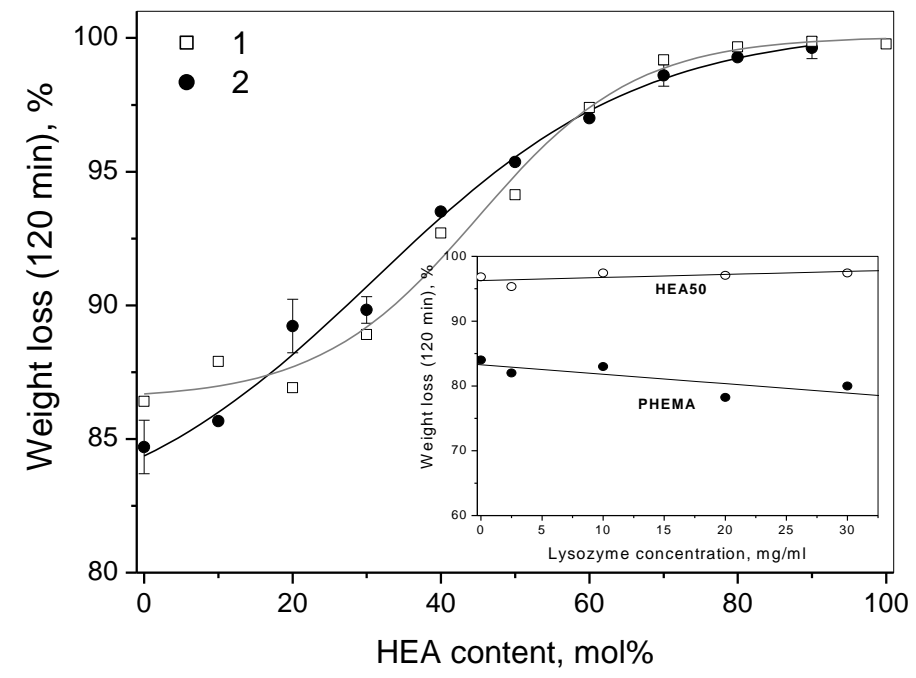

(b) 


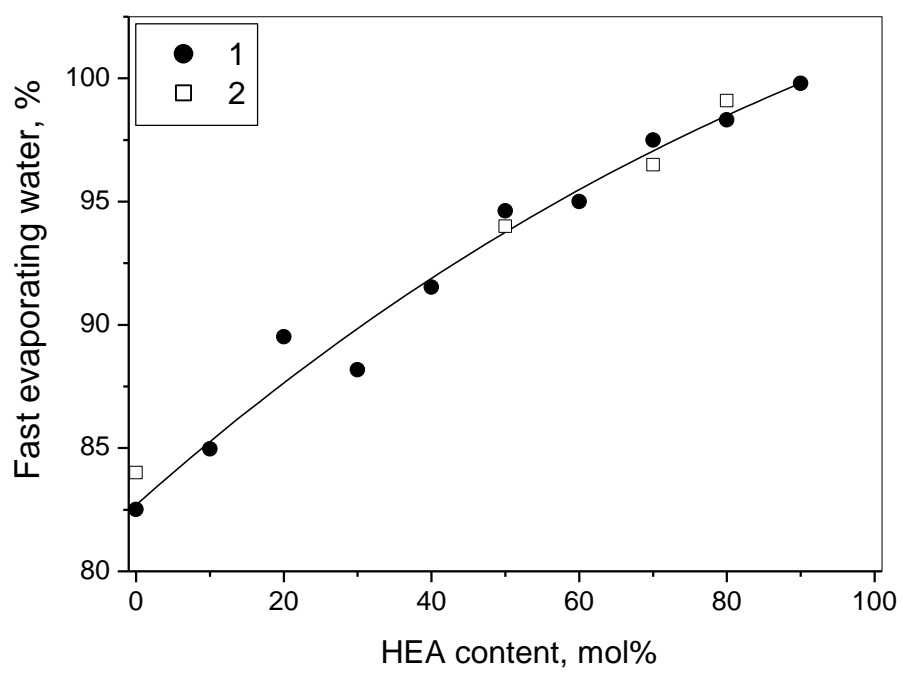

(c)

Fig. 4. Water retention properties of HEA-HEMA hydrogels studied by TGA (a). Typical "loss-on-drying" TGA curves illustrating change in hydrogel weight over time for HEA-HEMA hydrogels in $150 \mathrm{mM}$ PBS buffer containing $10 \mathrm{mg} / \mathrm{ml}$ lysozyme. Hydrogel samples were incubated at $37{ }^{\circ} \mathrm{C}$ during $120 \mathrm{~min}$; after $120 \mathrm{~min}$ hydrogels were heated up to $250{ }^{\circ} \mathrm{C}(120$ 150 min time interval). HEA content (mol\%) from top to bottom: 10, 20, 30, 40, 50, 70, 90. Insert: example of inflection point calculation using "Onset" option, TGA Pyris software (illustrated for HEA50 sample).

(b). Weight loss (\% of the total weight loss) during 120 -min incubation at $37{ }^{\circ} \mathrm{C}$ for hydrogels with different HEA content equilibrated in water (1) or in $150 \mathrm{mM}$ PBS buffer containing $10 \mathrm{mg} / \mathrm{ml}$ lysozyme (2). Solid lines - fitting of the experimental data to sigmoidal (Boltzmann) function.

Insert: Representative dependencies of the weight loss \% on the lysozyme concentration in the swelling medium for PHEMA and HEA50. Solid lines - fitting of the experimental data to linear function.

(c). Dependencies of the percentage of "fast" evaporating water on the HEA content for hydrogels fully equilibrated in buffered solution with (1) or without (2) lysozyme. Solid line - fitting of the experimental data to sigmoidal (Boltzmann) function. 


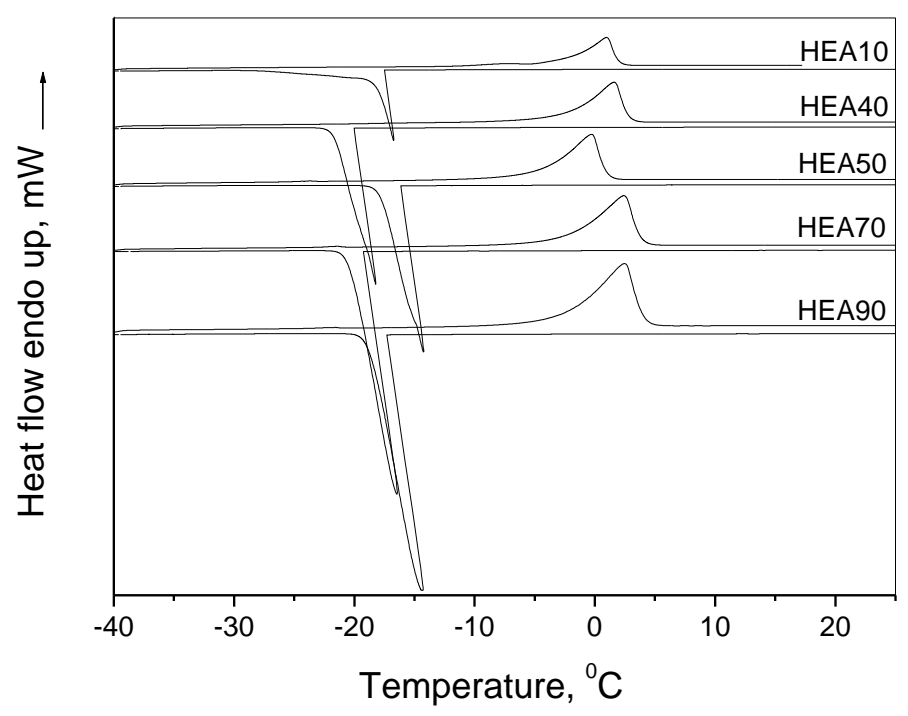

(a)

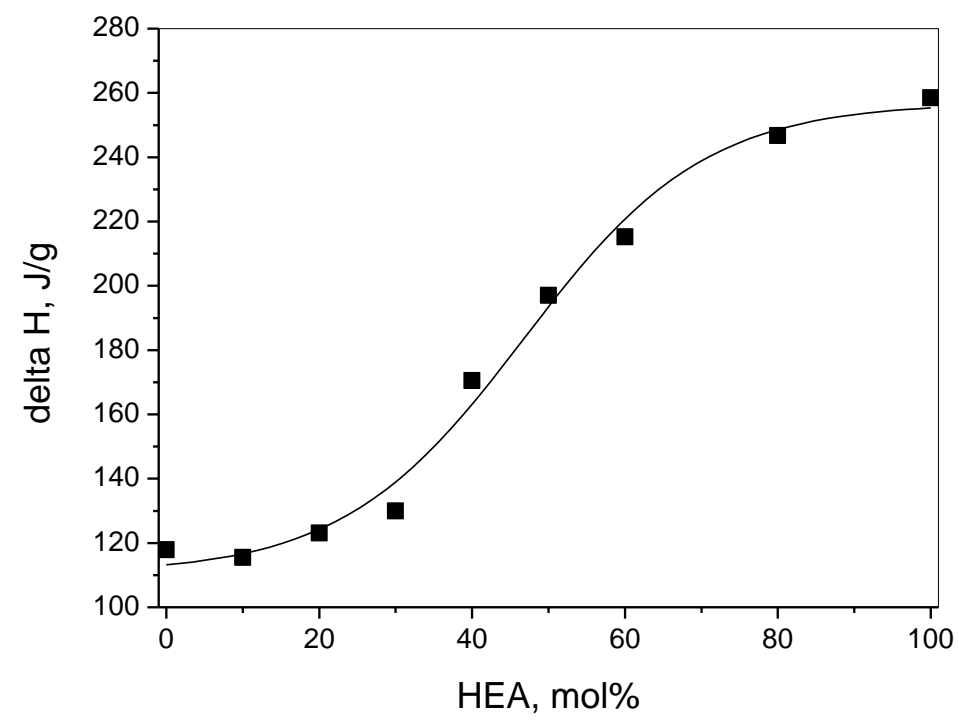

(b)

Fig. 5. DSC analysis of the thermal properties of water in HEA-HEMA hydrogels loaded with lysozyme.

(a) Typical DSC thermograms representing the freezing and subsequent melting curves for hydrogels equilibrated in $150 \mathrm{mM}$ PBS buffer containing lysozyme $(10 \mathrm{mg} / \mathrm{ml})$.

(b) Enthalpies of melting, $\Delta \mathrm{H}$, for freezing water in hydrogels with different HEA content fully equilibrated in lysozyme solution. Solid line - fitting of the experimental data to sigmoidal (Boltzmann) function. 


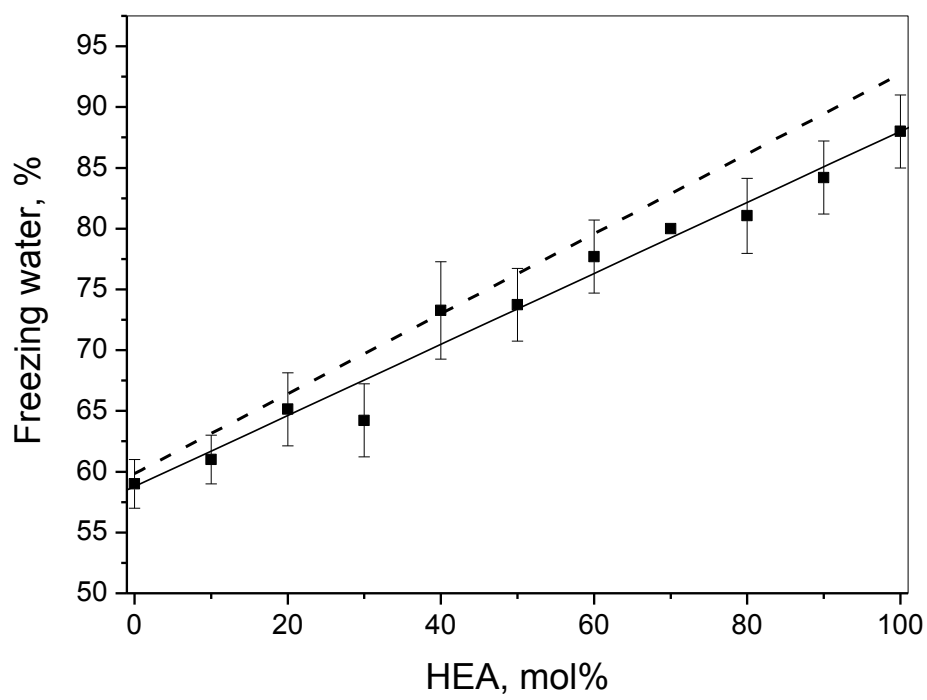

Fig. 6. Amount of freezing water (\% of the total water) in HEA-HEMA hydrogels with different HEA content equilibrated in buffered solution containing lysozyme $(10 \mathrm{mg} / \mathrm{ml})$. Solid line - fitting of the experimental data to linear function; Dash line - best fit for the amounts of freezing water in hydrogels fully swollen in water (data from (Hackl et al., 2015)). 


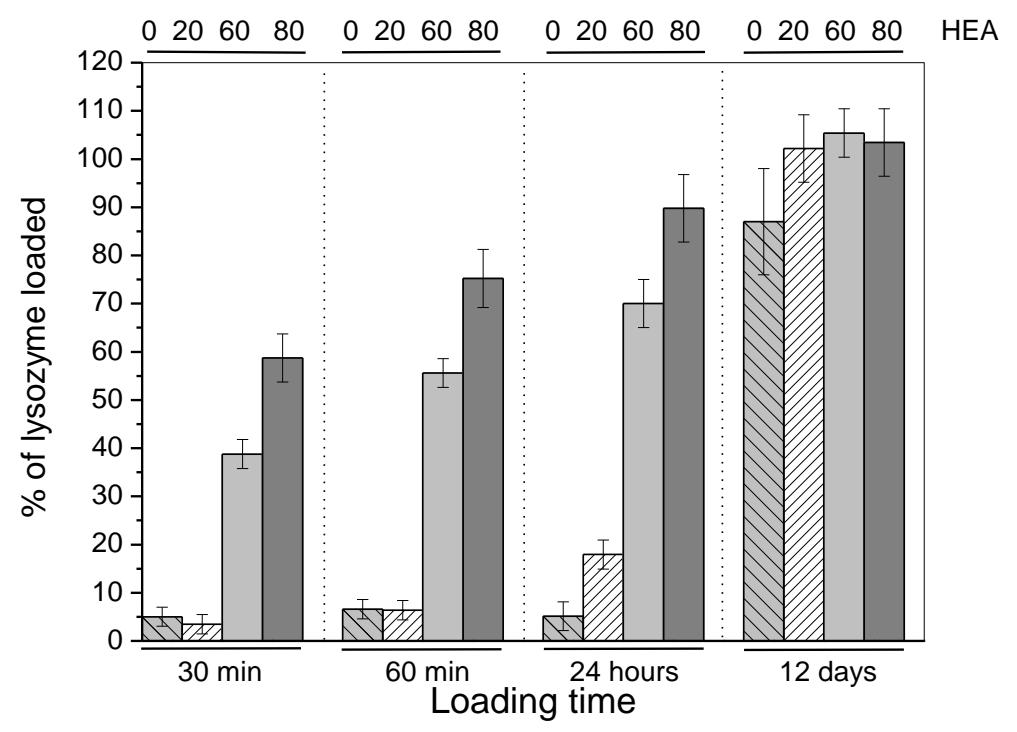

(a)

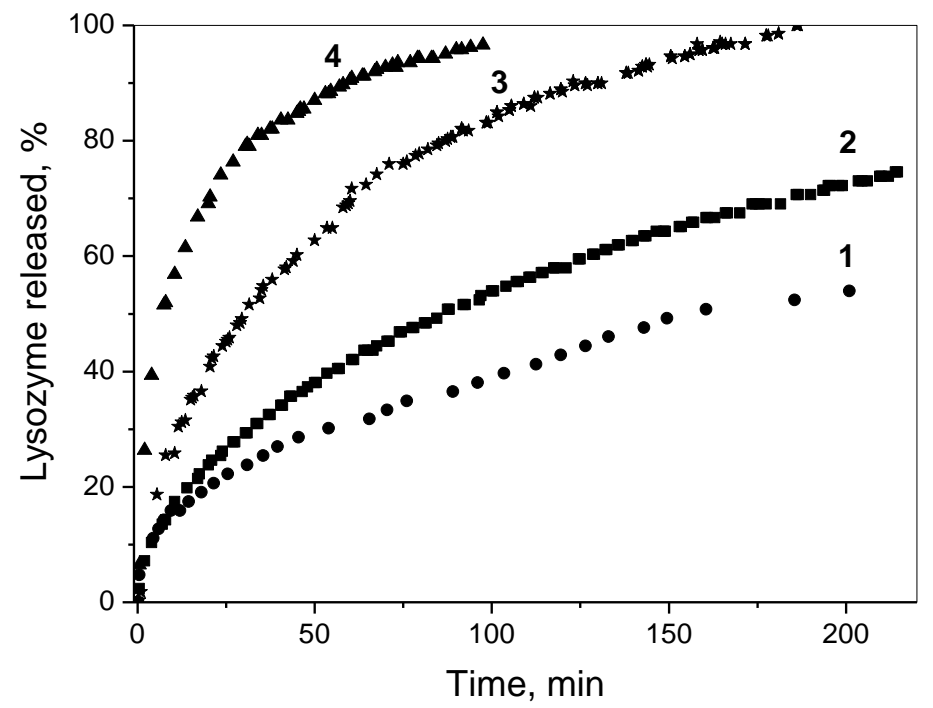

(b) 


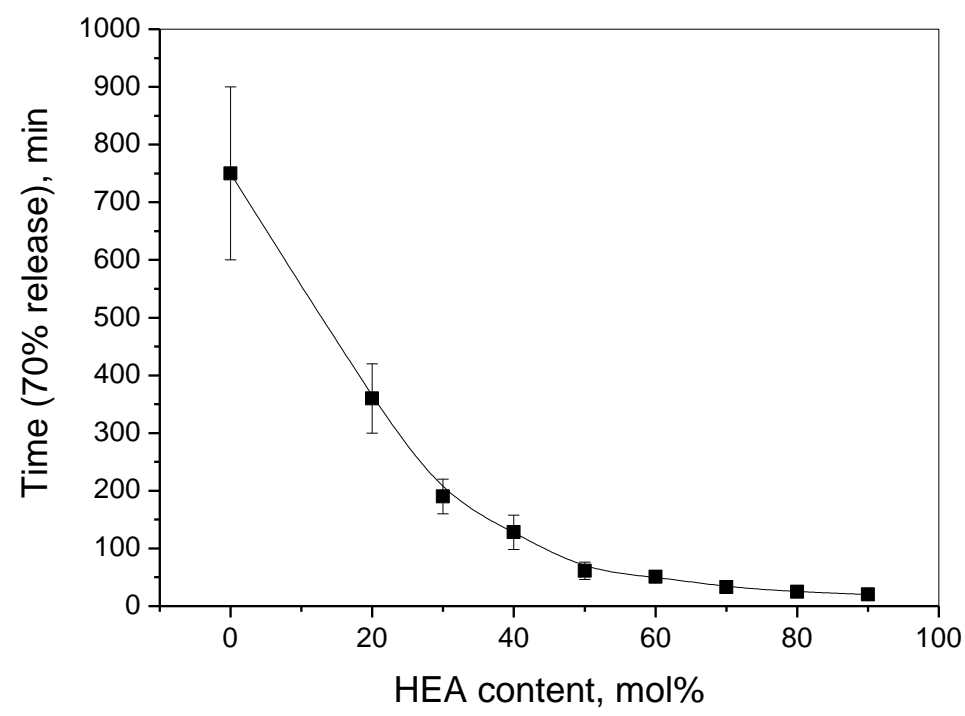

(c)

Fig. 7. In vitro lysozyme loading into and release from HEA-HEMA hydrogels with different HEA content.

(a). Estimated lysozyme concentrations in hydrogels (relatively to the lysozyme concentration in solution) vs. loading times (times of hydrogel incubation in buffered solution containing lysozyme (150 mM PBS, pH 7.4, $5 \mathrm{mg} / \mathrm{ml}$ of lysozyme, $\left.4{ }^{\circ} \mathrm{C}\right)$ ). HEA contents $(0,20,60,80)$ are indicated at the top.

(b). Release profiles for lysozyme. HEA content, mol\%: $1-20,2-30,3-50,4-80$. Before the experiment the hydrogels were soaked in $150 \mathrm{mM}$ PBS buffer containing $10 \mathrm{mg} / \mathrm{ml}$ lysozyme at $4{ }^{\circ} \mathrm{C}$ for 2-3 weeks.

(c). Dependencies of the times of $70 \%$ lysozyme release on the HEA content in hydrogels. Line is guide to the eyes only. 


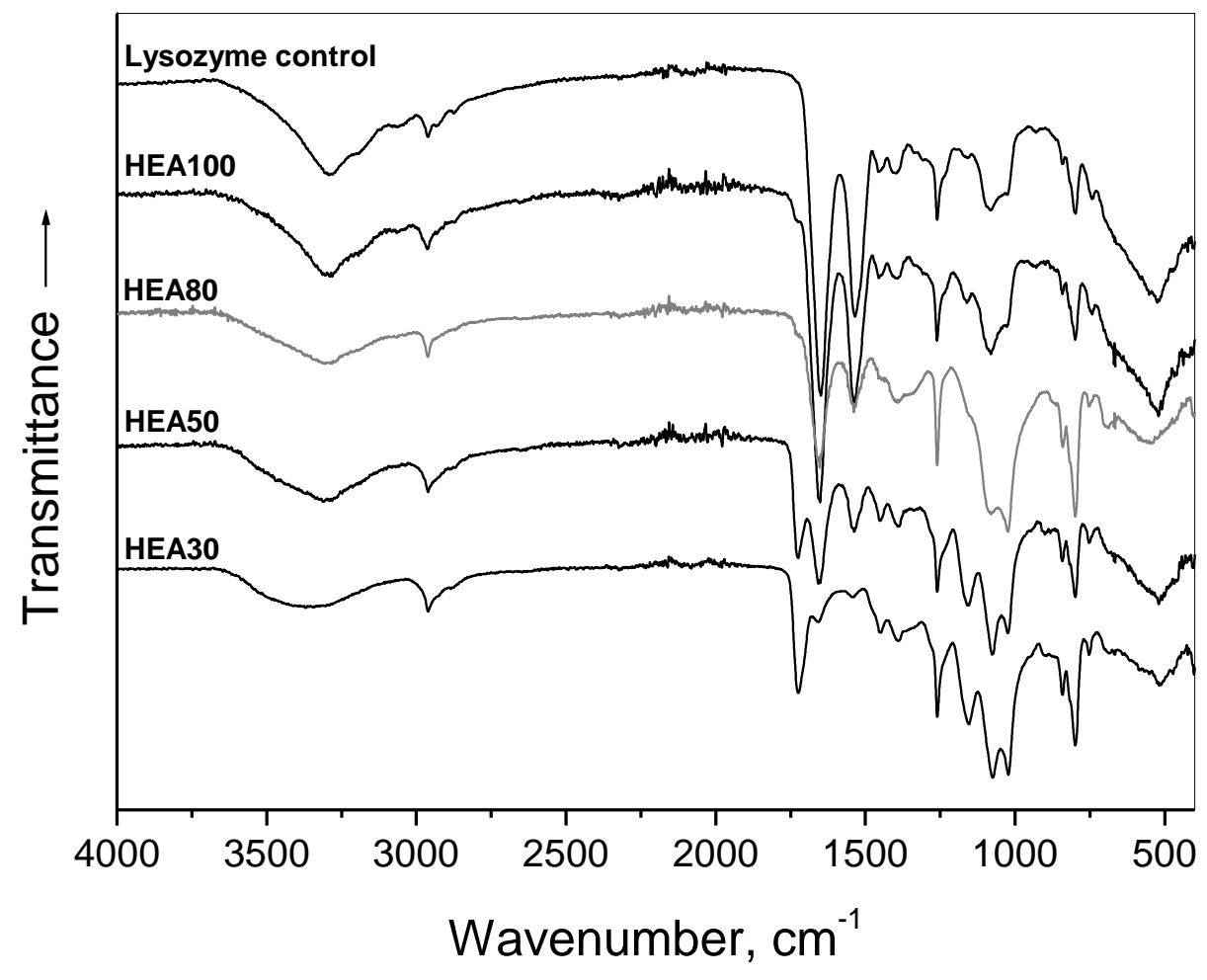

Fig. 8. ATR- FTIR spectra of freeze-dried lysozyme from freshly prepared aqueous solution (top) and released from HEA-HEMA hydrogels with different HEA content. All peak intensities were normalised to the intensity of the peak at $1260 \mathrm{~cm}^{-1}$. Peak around $1724 \mathrm{~cm}^{-1}$ is due to residual HEA material. 


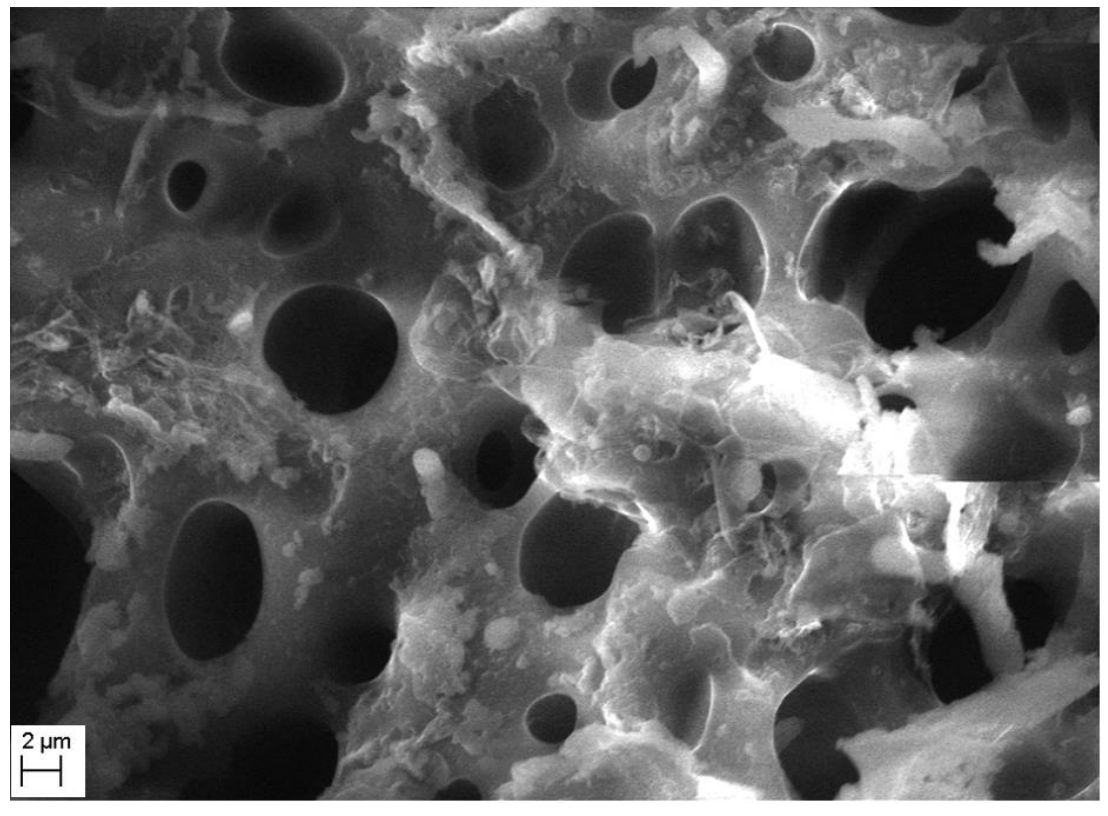

(a)

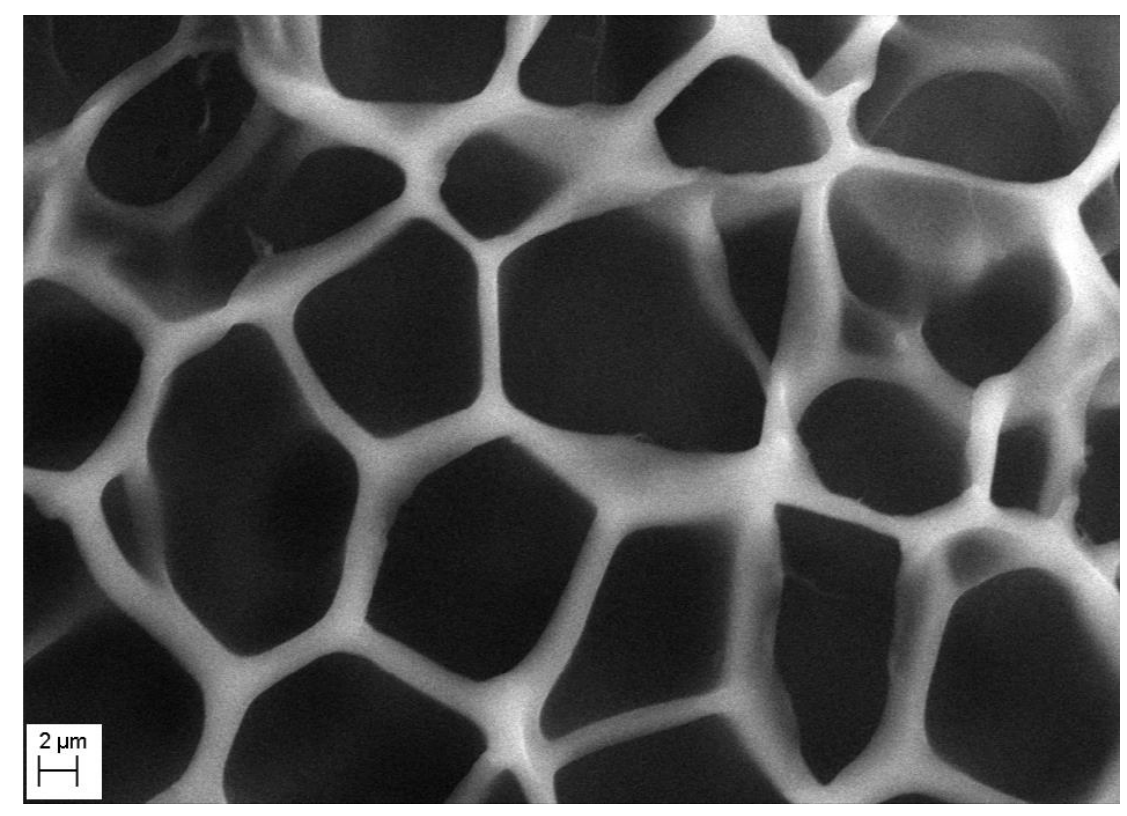

(b) 


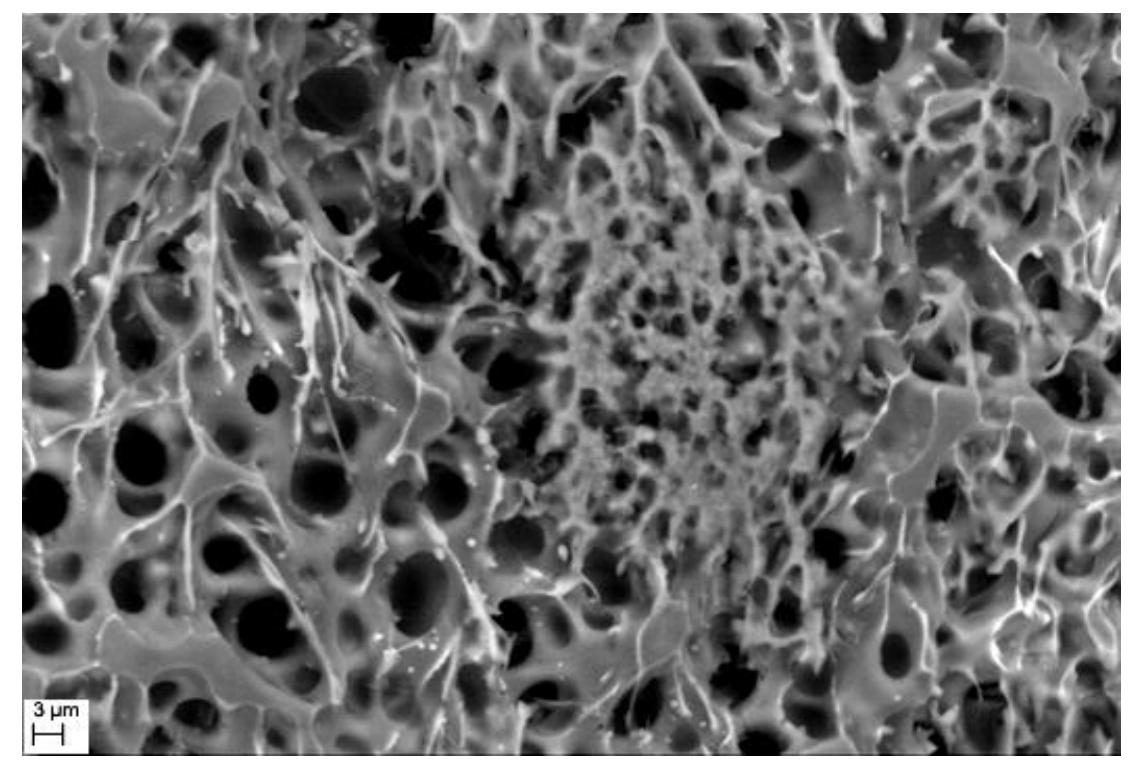

(c)

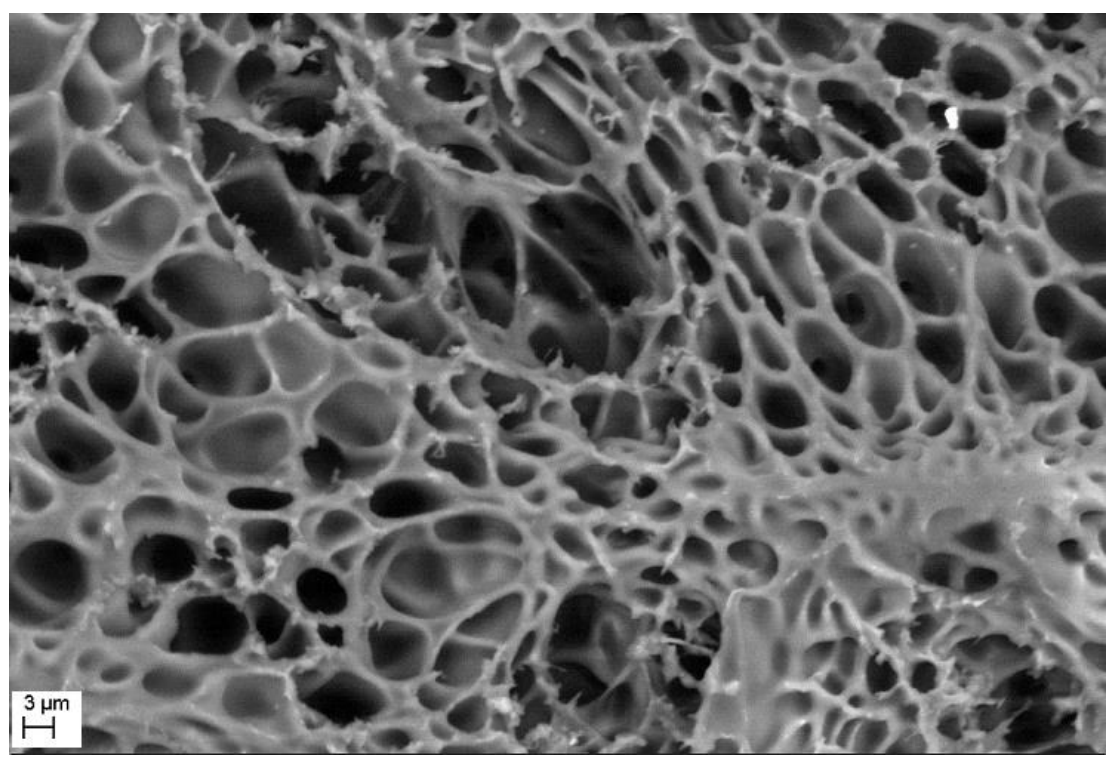

(d) 


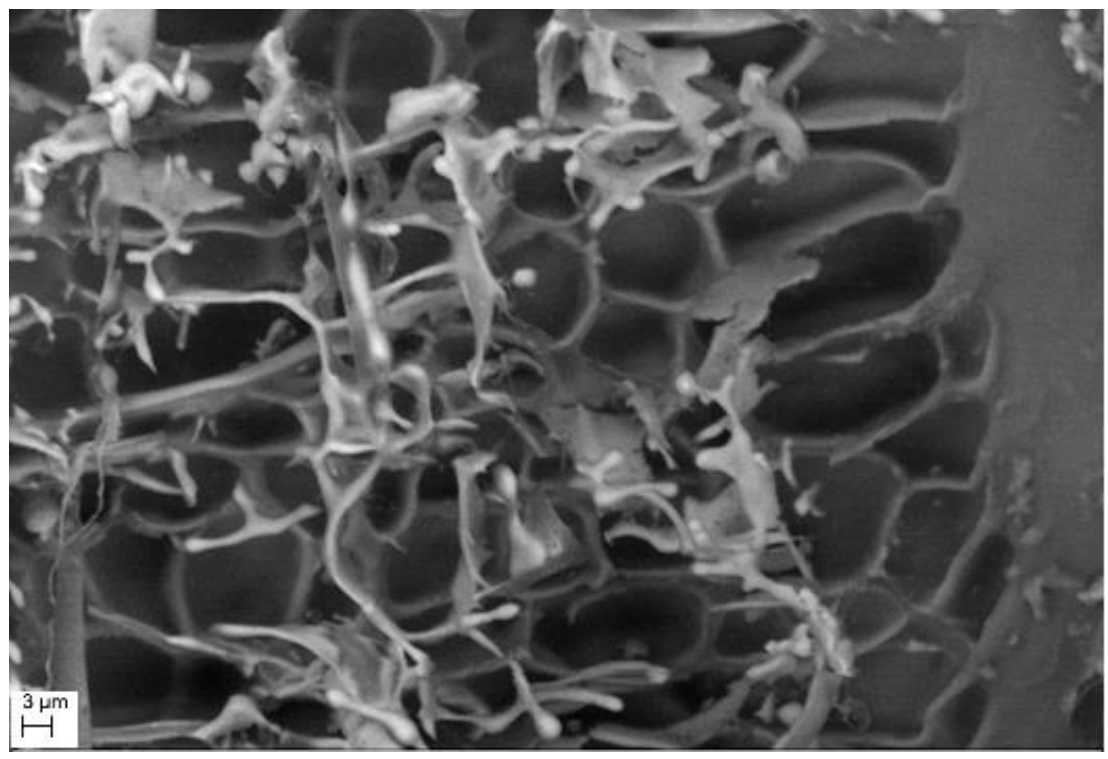

(e)

Fig. 9. SEM micrographs of the protein deposits on HEA-HEMA hydrogels immersed in $150 \mathrm{mM}$ PBS buffered solution containing lysozyme $(10 \mathrm{mg} / \mathrm{ml})$ during 1.5 month ((a) \& (b), x5000) at room temperature $\left(22{ }^{\circ} \mathrm{C}\right)$ or during 1 year at $\left.4{ }^{\circ} \mathrm{C}((\mathrm{c})-(\mathrm{e}), \mathrm{x} 2500)\right)$. HEA content, mol\%: (a) 0, (b) 70, (c) 10 , (d) 50 , (e) 80 . 


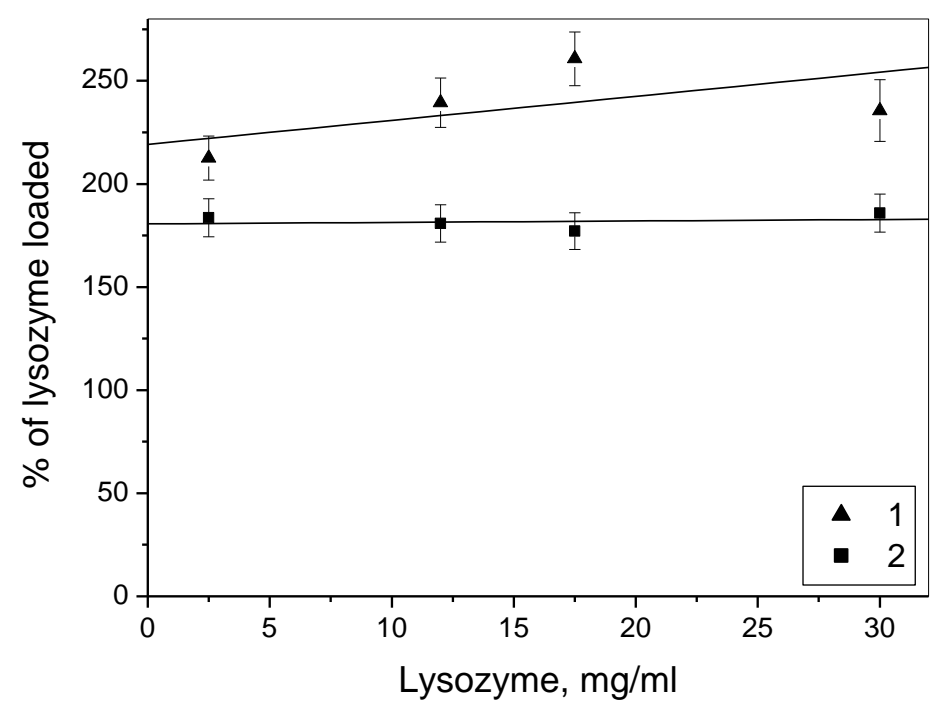

Fig. 10. Dependencies of the estimated lysozyme concentrations in hydrogels (relatively to the lysozyme concentration in solution) on the lysozyme concentration in solution used to incubate hydrogels in. HEA content, mol\%: $1-50,2-70$. Hydrogels were incubated in buffered $(150 \mathrm{mM}$ PBS, pH 7.4) lysozyme solution at $4{ }^{\circ} \mathrm{C}$ during 45 days.

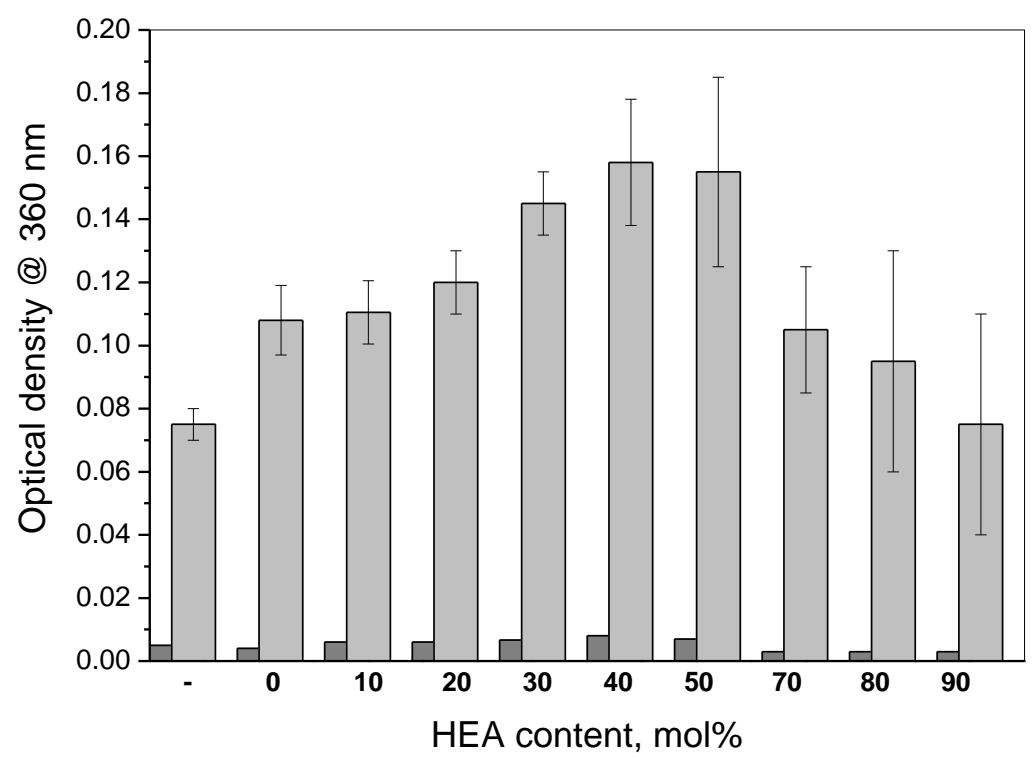

Fig. 11. Optical densities at $360 \mathrm{~nm}$ for lysozyme solutions (150 mM PBS buffer, pH 7.4, $2 \mathrm{mg} / \mathrm{ml}$ lysozyme) incubated for 1 day (dark columns) and 2 months (grey columns) with hydrogel fragments inside. Left sample (marked “-“) - lysozyme solution incubated in the absence of hydrogels. 


\section{Supplementary Figures}
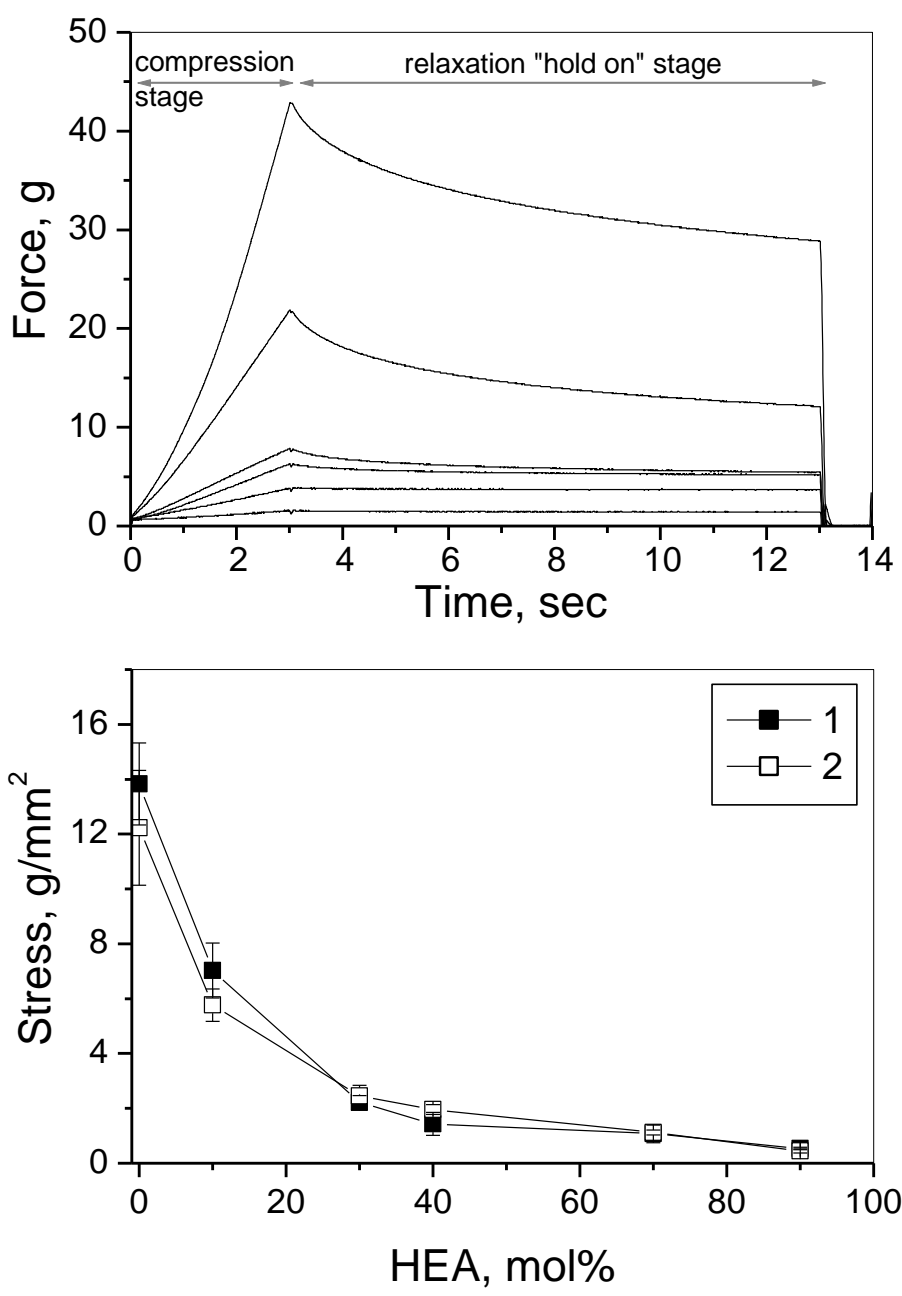

Fig. S1. Mechanical properties of HEA-HEMA hydrogels in buffer with / without lysozyme. (a). Representative force vs. time curves for HEA-HEMA hydrogels in $150 \mathrm{mM}$ PBS buffer containing $2 \mathrm{mg} / \mathrm{ml}$ of lysozyme. HEA content, mol\% (from top to bottom): 0, 10, 30, 40, 70, 90. Hydrogels were incubated in solution containing lysozyme at room temperature 1 month before measurements.

(b). Dependence of the stress on HEA content for hydrogels fully swollen in $150 \mathrm{mM}$ PBS buffer without (1) or with (2) lysozyme. 


\section{References}

1. Peppas, N.A., Bures, P., Leobandung, W. and Ichikawa, H. Eur. J. Pharm. Biopharm. 2000, 50, 27-46.

2. Caló, E. and Khutoryanskiy, V.V. Eur. Polymer J. 2015, 65, 252-267.

3. Kim, J.K., Kim, H.J., Chung, J.Y., Lee, J.H., Young, S.B. and Kim, Y.H. Arch. Pharm. Res. 2014, $1,60-68$.

4. Choonara, B.F., Choonara, Y.E., Kumar, P., Bijukumar, D., du Toit, L.C. and Pillay, V. Biotechnol. Adv. 2014, 32, 1269-1282.

5. Leader,B., Baca, Q.J. and Golan, D.E. Nat. Rev. Drug Discov. 2008, 7, 21-39.

6. Oey, M., Lohse, M., Scharff, L.B., Kreikemeyer, B. and Bock, R. Proc. Natl. Acad. Sci. U S A. 2009, 106, 6579-6584.

7. Housden, N.G. and Kleanthous, C. Biochem. Soc. Trans. 2012, 40, 1475-1479.

8. Kim, Y.C., Tarr, A.W. and Penfold, C.N. Biochim. Biophys. Acta 2014, 1843, 1717-1731.

9. Lohcharoenka,W., Wang,L., Chen,Y.C. and Rojanasakul, Y. BioMed. Res. Int. 2014, 2014, 180549-180561.

10. Dolman, M.E., Harmsen, S., Storm, G., Hennink, W.E. and Kok, R.J. Adv. Drug Deliv. Rev. 2010, 62, 13444-13457.

11. Barrientos, S., Brem, H., Stojadinovic, O. and Tomic-Canic, M. Wound Repair Regen. 2014, 22(5), 569-578.

12. Mann, M.J. and Dzau, V.J. J. Clin. Invest. 2000, 106(9), 1071-1075.

13. Carrillo-Conde, B.R., Brewer E., Lowman, A. and Peppas, N.A. Ind. Eng. Chem. Res. 2015, 54, 10197-10211.

14. Tuesca, A., Nakamura, K., Morishita, M., Joseph, J., Peppas, N. and Lowman, A. J. Pharm. Sci. 2008, 97, 2607-2618. 
15. Kim, B. and Peppas, N.A. Int. J. Pharm. 2003, 266, 29-37.

16. Khutoryanskaya, O.V., Mayeva, Z.A., Mun, G.A. and Khutoryanskiy, V.V. Biomacromolecules 2008, 9, 3353-3361.

17. Hackl, E. V., Khutoryanskiy, V. V., Tiguman, G. M. B. and Ermolina, I. J. of Therm. Anal. and Calorim. 2015, 121, 335-345.

18. Roach, P., Farrar, D. and Perry, C.C. J. Am. Chem. Soc. 2005, 127, 8168-8173.

19. Norde, W. In Biopolymers at Interfaces; Malmsten, M., Ed.; Marcel Dekker: New York, 2003; pp 21-43.

20. Leahy, C.D., Mandell, R.B. and Lin, S.T. Optom. Vis. Sci. 1990, 67, 504-511.

21. Luensmann, D. and Jones, L. Cont.Lens. Anterior. Eye. 2012, 35, 53-64.

22. Mann, A. and Tighe, B. Exp. Eye. Res. 2013, 117, 88-98.

23. Sassi, A. P., Lee, S.-H., Park, Y. H., Blanch, H. W. and Prausnitz, J. M. J. Appl. Polym. Sci. 1996, 60, 225-234.

24. Garrett, Q., Garrett, R.W. and Milthorpe, B.K. Invest. Ophthalmol. Vis. Sci. 1999, 40, 897-903. 25. Lord, M.S., Stenzel, M.H., Simmons, A. and Milthorpe, B.K. Biomaterials 2006, 27, 567-575. 26. Ng, A., Heynen, M., Luensmann, D., Subbaraman, L. N. and Jones, L. J. of Biomed. Mat. Res. Part B, 2013, 101, 1172-1181.

27. Protein Misfolding, Aggregation and Conformational Diseases: Part B: Molecular Mechanisms of Conformational Diseases; Uversky, V.N. and Fink, A., Eds.; Springer Science + Business Media, LLC, New York, 2007.

28. Ritger, P.L., and Peppas, N.A. J. Controlled Release 1987, 5, 37-42.

29. De Kee, D., Liu, Q. and Hinestroza, J. Canad. J. of Chem. Engin. 2005, 6, 913-929.

30. Katime, I. and Mendizábal, E. Materials Sci. \& Applicat. 2010, 1, 162-167. 
31. Wang J., Wu W. and Lin Z. J. Appl. Polym. Sci. 2008, 109, 3018-3028.

32. John, M.S. and Andrade, J.D. J. Biomed. Mater. Res. 1973, 7, 509-515.

33. Bouwstra, J.A., Salomon-de Vries, M.A., and van Miltenburg, J.C. Thermochimica Acta 1995, 248, 319-327.

34. Flynn, G.L., Yalkowsky, S.H. and Roseman, T.J. J. Pharm. Sci. 1974, 63, 479-510.

35. Goldfarb, A.R., Saidel, L.J. and Mosovich, E. J. Biol. Chem. 1951, 193, 397-404.

36. Flores-Fernández, G.M., Solá, R.J. and Griebenow, K. J. Pharm. Pharmacol. 2009, 61(11), $1555-15561$.

37. Analysis of aggregates and particles in protein pharmaceuticals; Mahler, H.-C. and Jiskoot, W., Eds.; John Wiley \& Sons: Hoboken, NJ, 2012.

38. Sassi, P., Giugliarelli, A., Paolantoni, M., Morresi, A. and Onori, G. Biophys Chem., 2011, 158, 46-53.

39. Barth, A. Biochim. Biophys. Acta. 2007, 1767, 1073-1101.

40. Carpenter, J.F., Prestrelski, S.J. and Dong, A. Eur. J. Pharm. Biopharm. 1998, 45, 231-238.

41. Griebenow, K. and Klibanov, A.M. Proc. Natl. Acad. Sci. U S A. 1995, 92, 10969-10976.

42. Lord, M.S., Stenzel, M.H., Simmons, A. and Milthorpe, B.K. Biomaterials 2006, 27, 1341-1345. 43. Lin, S.T., Mandell, R.B., Leahy, C.D. and Newell, J.O. CLAO J. 1991, 17, 44-50.

44. Kingshott, P., St. John, H.A., Chatelier, R.C. and Griesser, H.J. J. Biomed. Mater. Res. 2000, 49, $36-42$.

45. van Beek, M., Weeks, A., Jones, L. and Sheardown, H. J. Biomater. Sci. Polym. Ed. 2008, 19, $1425-1436$.

46. Cassinelli, C., Morra, M., Pavesio, A. and Renier, D. J. Biomater. Sci. Polym. Ed. 2000, 11, 961977.

47. Garrett, Q., Laycock, B. and Garrett, R.W. Invest. Ophthalmol. Vis. Sci. 2000, 41, 1687-1695. 
48. Holly, F.J. and Refojo, M. F. J. Biomed. Mater. Res. 1975, 9, 315-326.

49. Hawe, A., Sutter, M. and Jiskoot, W. Pharm. Res. 2008, 25, 1487-1499.

50. Castillo, E.J., Koenig, J.L., Anderson, J.M. and Lo, J. Biomaterials 1984, 5(6), 319-325.

51. Castillo, E.J., Koenig, J.L., Anderson, J.M. and Lo, J. Biomaterials 1985, 6(5), 338-345. 